\section{O PERFIL DA PRODUÇÃO DE ARTIGOS RELACIONADOS COM O ESPORTE NOS PROGRAMAS DE PÓS-GRADUAÇÃO EM EDUCAÇÃO FÍSICA NO BRASIL (2010-2016)}

\author{
THE PROFILE OF SPORTS-RELATED ARTICLES PRODUCED IN \\ PHYSICAL EDUCATION GRADUATE PROGRAMS (2010-2016)
}

\author{
EL PERFIL DE LA PRODUCCIÓN DE ARTÍCULOS RELACIONADOS CON \\ EL DEPORTE EN LOS PROGRAMAS DE POSGRADO EN EDUCACIÓN \\ FÍSICA EN BRASIL (2010-2016)
}

\section{Doralice Lange de Souza*, Andressa Caroline Portes da Cunha*}

Palavras chave:

Esportes.

Bibliometria.

Conhecimento.

Educação Física.

Keywords:

Sports.

Bibliometrics.

Knowledge.

Physical

Education.

Palabras clave: Deportes.

Bibliometría.

Conocimiento.

Educación Física.
Resumo: Investigamos, a partir de uma perspectiva quanti-qualitativa, algumas características da produção de artigos por parte de programas de pós-graduação em Educação Física entre 2010 e 2016, relacionados com o esporte. Utilizamos como fontes os relatórios anuais dos programas e os próprios artigos. Os programas produziram 3.252 artigos, sendo os mais produtivos: PPGEFE/EEFE/USP, PPGFEF/UNICAMP e PPGEF/UEM-UEL. A maior parte da produção relaciona-se com a subárea biodinâmica $(70 \%)$, seguida pela sociocultural $(21 \%)$ e pedagógica (8\%). Na subárea biodinâmica destaca-se o PPGEFE/EEFE/USP, na sociocultural o PPGEDF/UFPR, e na pedagógica o PPGFEF/UNICAMP. A produção cresceu entre 2010 e 2016. Em 2016, houve mais artigos em língua estrangeira do que em português. Enquanto o número de artigos da subárea biodinâmica expandiu significativamente, o das outras subáreas não. Algumas dessas características estão correlacionadas com as particularidades das diferentes subáreas de conhecimento e com os critérios de avaliação da Capes (Área 21).

Abstract: From a quantitative-qualitative perspective, we investigated some features of sports-related articles published by Physical Education graduate programs from 2010 to 2016 . Our sources of information were the programs' annual reports and the articles themselves. The programs published 3,252 articles, and the most productive ones were PPGEFE/EEFE/USP, PPGFEF/UNICAMP, and PPGEF/UEM-UEL. Most articles are related to biodynamics (70\%), followed by the socio-cultural $(21 \%)$ and pedagogic $(8 \%)$ subfields. PPGEFE/EEFE/USP stands out in biodynamics, PPGEDF/UFP leads in the sociocultural area, and PPGFEF/ UNICAMP has the largest production in the pedagogical subfield. The number of articles increased from 2010 to 2017; in 2016, articles in foreign language outnumbered those written in Portuguese. While the number of publications on biodynamics has grown significantly, that on the other areas has not. Some of these characteristics are related to peculiarities of these different subfields and to evaluation criteria adopted by CAPES (Area 21).

Resumen: Investigamos, desde una perspectiva cuanti-cualitativa, algunas características de la producción de artículos por parte de programas de postgrado en Educación Física entre 2010 y 2016, relacionados con el deporte. Utilizamos como fuente los informes anuales de los programas y los propios artículos. Los programas produjeron 3.252 artículos, y los más productivos fueron: PPGEFE/ EEFE/USP, PPGFEF/UNICAMP y PPGEF/UEM-UEL. La mayor parte de la producción se relaciona con la subárea biodinámica $(70 \%)$, seguida por la sociocultural $(21 \%)$ y por la pedagógica $(8 \%)$. En la biodinámica se destaca el PPGEFE/EEFE/USP, en la sociocultural el PPGEDF/UFPR y en la pedagógica, el PPGFEF/UNICAMP. La producción creció entre 2010 y 2016 y, en 2016, hubo más artículos en idioma extranjero que en portugués. Mientras que el número de artículos de la subárea biodinámica se amplió significativamente, el de las otras subáreas no. Algunas de estas características están correlacionadas con las particularidades de las diferentes subáreas de conocimiento y con los criterios de evaluación de la CAPES (Área 21).
* Universidade Federal do Paraná. Curitiba, PR, Brasil. E-mail: desouzdo@yahoo.com; andressa.cpcunha@hotmail.com

Recebido em: 25-02-2019 Aprovado em: 02-08-2019 Publicado em: 03-02-2020 


\section{INTRODUÇÃO}

O esporte é um importante fenômeno sociocultural que apresenta múltiplas finalidades, sentidos e significados. Dentre suas diferentes funções, ele pode se constituir, por exemplo, como meio de negócios, profissão, lazer, saúde, estética, reabilitação, socialização e educação. Fazendo-se presente em diferentes esferas da vida, tais como família, mídia, política, mídia e escola, ele reafirma importantes valores, crenças e ideologias (COAKLEY, 2015). Considerando a relevância e complexidade desse fenômeno, desenvolvemos um estudo com o objetivo de mapear as características da produção de artigos dos Programas de Pós-Graduação em Educação Física (PPGEF) que direta ou indiretamente ${ }^{1}$ discutem o esporte de uma forma geral e/ou modalidades esportivas com federações internacionais ou adaptações destas modalidades em específico, tendo em vista o esporte em suas diferentes manifestações (rendimento, lazer, formação, participação e educação) ${ }^{2}$. Mais especificamente, visamos identificar: (1) o número total de artigos produzidos como um todo e por programa; (2) as subáreas de conhecimento dos artigos em geral e por programa; (3) os idiomas das publicações em geral, por programa e por subárea de conhecimento; (4) o perfil numérico das coautorias de uma forma geral e por subáreas de conhecimento; (5) a participação de órgãos de fomento na produção de artigos em geral e por subárea de conhecimento; (6) hipóteses que possam ajudar a explicar algumas destas características.

Esta pesquisa é parte de um projeto maior intitulado "Inteligência Esportiva", financiado pelo Ministério do Esporte. Para este trabalho, consideramos apenas a produção de artigos em revistas com os estratos Qualis A1 a B5 dos programas de pós-graduação (PPG) stricto sensu da Educação Física que declararam a sua produção entre 2010 e 2016.

Para a análise das subáreas de conhecimento dos artigos, nos baseamos em Manoel e Carvalho (2011, p. 392), que caracterizaram a EF de acordo com a sua aproximação com três subáreas de concentração - biodinâmica, sociocultural e pedagógica.

A biodinâmica compreende as atividades de pesquisa dentro de subdisciplinas como bioquímica do exercício, biomecânica, fisiologia do exercício, controle motor, aprendizagem e desenvolvimento motor [...]. As linhas de pesquisa na biodinâmica são orientadas pelas ciências naturais [...]. A subárea sociocultural trata de temas como esporte, práticas corporais e atividade física nas perspectivas da sociologia, da antropologia, da história e da filosofia. A subárea pedagógica investiga questões relativas à formação de professores, ao desenvolvimento curricular, aos métodos de ensino e à pedagogia do esporte, além de tratar de aspectos metodológicos, sociais, políticos e filosóficos da educação. As subáreas sociocultural e pedagógica definem suas linhas de investigação orientadas pelas ciências sociais e humanas.

Focamos na produção de conhecimentos dos PPGEF por serem estas as instâncias que mais produzem sobre o esporte no país (SOUZA; SILVA; MOREIRA,

\footnotetext{
1 Incluímos artigos que, embora não tenham como foco uma discussão sobre o esporte em si, diretamente subsidiam o seu desenvolvimento. Os critérios de inclusão e exclusão de artigos melhor esclarecem esta questão.

2 Estas são as manifestações de acordo com a legislação brasileira. Disponível em: http://www.planalto.gov.br/ ccivil_03/LEIS/L9615consol.htm. Acesso em: 20 mar. 2018.
} 
2016). Estudos sobre a produção do conhecimento nos PPG podem contribuir para com o autoconhecimento da área (LAZZAROTTI FILHO et al., 2012), bem como revelam tendências de futuros estudos, uma vez que se dedicam à formação de pesquisadores (JOB, 2006). Ao revelar pontos fortes e frágeis da produção e hipóteses que possam explicar o atual perfil da produção, geraremos subsídios para futuras pesquisas no campo e fomento de estudos em áreas mais carentes e/ou estratégicas do esporte.

\section{PROCEDIMENTOS METODOLÓGICOS}

Este trabalho é de cunho quanti-qualitativo e exploratório. Tomamos como base alguns indicadores da bibliometria, como, por exemplo, o número e a distribuição das publicações (SANCHO, 1990) e nos inspiramos em procedimentos da revisão sistemática (TULDER, 2003). Primeiramente realizamos um levantamento dos PPG stricto sensu em EF que tinham produção declarada para a Capes no período de 2010 a $2016^{3}$, utilizando a Plataforma Sucupira e arquivos digitais fornecidos pela coordenação da Área 21. A seguir, realizamos uma análise dos relatórios anuais de avaliação de cada um desses programas. Mapeamos os títulos dos artigos lançados nos relatórios e publicados em revistas estratificadas no Qualis A1 a B5. Selecionamos os trabalhos que possivelmente discutiam o esporte e analisamos os seus resumos e/ou trechos dos artigos, para verificar se eles entravam no escopo do levantamento. Quando as modalidades não eram olímpicas ou paralímpicas, pesquisávamos se elas contavam com federações internacionais ou eram adaptações de modalidades federadas. Quando positivo, incluímos os seus nomes em nossa lista de descritores. Adotamos também outros termos de busca que poderiam indicar a presença de discussões relacionadas com o esporte, tais como: esporte, competição, paradesporto, paradesportivo, copa do mundo, jogos olímpicos, jogos paraolímpicos, prática esportiva, modalidade esportiva, performance, atleta, desempenho aeróbio/ aeróbico/anaeróbico/anaeróbio, treinamento, currículo de educação física. Incluímos também nomes de equipamentos, espaços e animais utilizados para a prática de modalidades esportivas; a designação utilizada para os praticantes das modalidades (ex. tenista, basquetebolista, nadador) e nomes antigos e/ou popularmente conhecidos das modalidades.

Adotamos os seguintes critérios de inclusão: (1) Artigos de revistas com estrato Qualis A1 a B5 com os descritores no título, resumo ou palavras-chave que tratam de tópicos pertinentes ao esporte e/ou modalidades esportivas com federações internacionais (CFI), considerando o esporte em suas diferentes manifestações. (2) Trabalhos que tratam de modalidades que, embora não tenham federações internacionais, são adaptações de modalidades (ADMO) que as têm (ex. corrida de rua, corrida de $1.600 \mathrm{~m}$, handebol adaptado). (3) Trabalhos que contêm os descritores em seu resumo e/ou assunto e que, embora não discutam nenhuma modalidade em específico, tratam de temas que se aplicam a elas e/ou aos seus praticantes (ex. estratégias para melhorar desempenho aeróbio de atletas). (4) Trabalhos que mencionam testes e/ou experimentos com atletas de modalidades esportivas CFI

\footnotetext{
3 Excluímos os relatórios dos Programas da Fisioterapia, Fonoaudiologia e Terapia Ocupacional. Embora eles façam parte da Área 21, eles têm particularidades que, considerando o escopo deste trabalho, não teríamos como explorar neste momento.
} 
ou ADMO. (5) Trabalhos que fazem testes com diferentes tipos de atividade física e/ ou equipamentos esportivos (ex. corrida, bicicleta ergométrica, natação, caminhada etc.) e que fazem relação com as modalidades esportivas CFI ou ADMO e/ou com os seus praticantes. (6) Trabalhos que discutem espaços, equipamentos e animais utilizados em modalidades CFI ou ADMO (ex. bicicletas, pistas de corrida, raquetes, cavalos utilizados no hipismo). (7) Trabalhos que envolvem animais e que explicitam implicações diretas para uma ou mais modalidades CFI ou ADMO e/ou efeitos dessas modalidades em humanos.

Os critérios de exclusão foram: (1) Artigos que discutem a dança. Embora ela conte com federação internacional, devido à amplitude de seus desdobramentos, não foi considerada para fins deste estudo. (2) Artigos que tratam do ciclismo enquanto meio de transporte sem correlacioná-lo com a prática esportiva. (3) Artigos que tratam de testes que envolvem animais, modalidades ou equipamentos esportivos (ex. corrida, arremesso de peso, natação, ciclismo, testes de força, bicicleta ergométrica, supino) sem menção à aplicação prática dos resultados para modalidades esportivas CFI ou ADMO e/ou para os seus praticantes.

Quanto aos procedimentos metodológicos para a definição dos descritores, coleta, tabulação, análise dos dados, nos inspiramos em Tulder et al. (2003). A equipe de pesquisa, que contou com alunos bolsistas e voluntários, se reuniu semanalmente para refinar os descritores, critérios de inclusão e exclusão e categorização dos dados. Nestes encontros também discutíamos dúvidas e testávamos nossos critérios e formas de categorização até alcançarmos consenso nos resultados. Tabulamos os dados em uma planilha Excel a partir de uma leitura detalhada dos metadados, do resumo, e quando necessário, de outras partes dos artigos, considerando diferentes tipos de informação, conforme exemplo no quadro 1 (páginas 5 e 6).

Ressaltamos que, dentre alguns resultados que apresentaremos, em alguns casos a soma de artigos e/ou de percentuais relativos a algumas de suas características é maior do que o número total de trabalhos analisados. Isso ocorre porque um mesmo artigo pode ter sido produzido por pesquisadores provenientes de diferentes programas. Ele pode também ter sido produzido a partir de uma perspectiva interdisciplinar e, portanto, classificado em mais de uma área de conhecimento.

\section{RESULTADOS E DISCUSSÃO}

Organizamos a apresentação dos resultados da seguinte forma: primeiramente discorremos sobre os programas que produziram sobre o esporte no período analisado, destacando os mais produtivos. A seguir apresentamos uma discussão sobre as subáreas do conhecimento presentes na produção de uma forma geral e por programa. Na sequência, discorremos sobre os idiomas dos artigos. Por fim, expomos os índices de coautorias presentes na produção. Ao término da seção, exploramos como alguns dos fatores apresentados como hipóteses para explicar o perfil da produção podem estar se retroalimentando no sentido de mantê-lo. 
Quadro 1 - Exemplo de uma das formas de tabulação dos dados

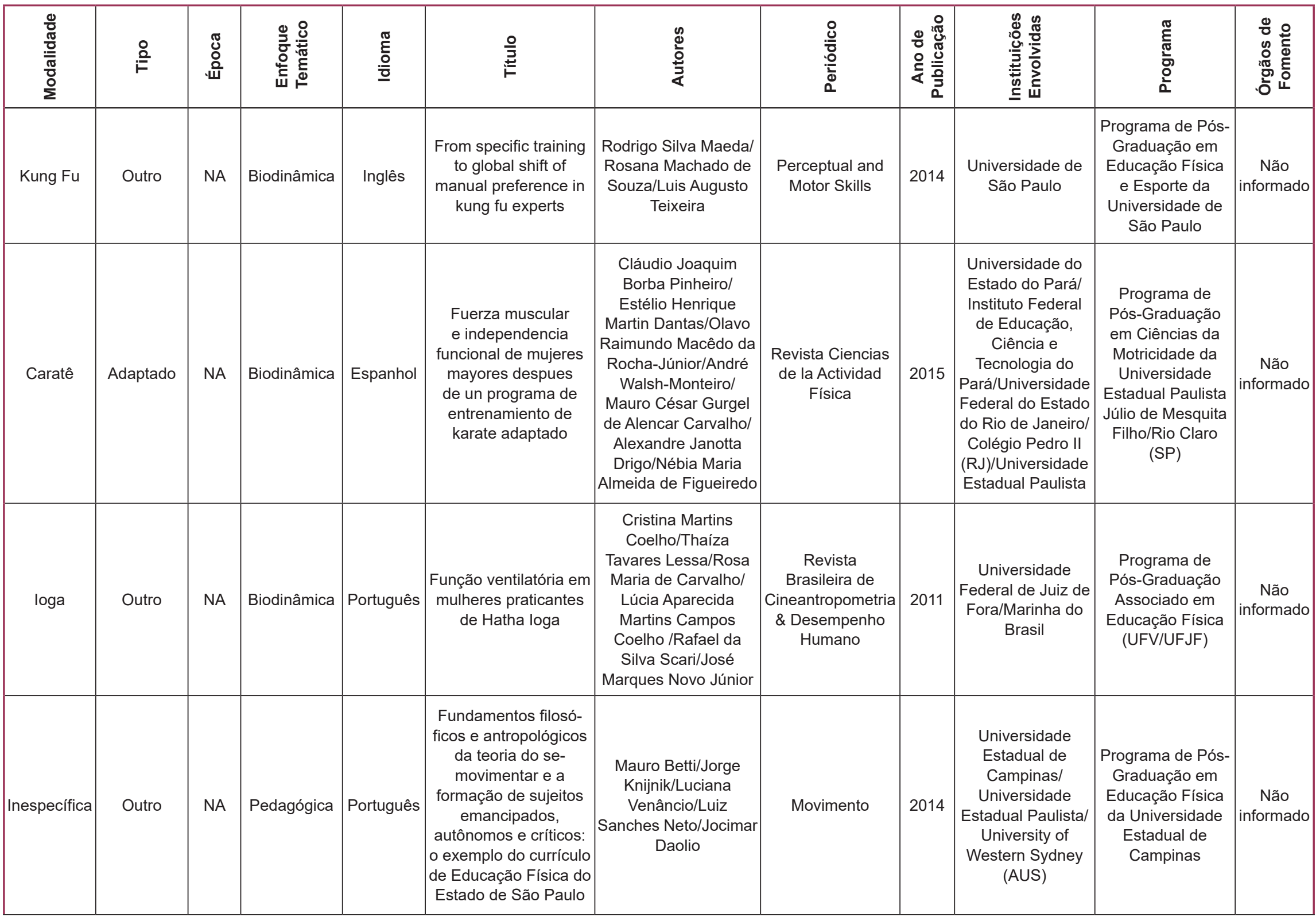

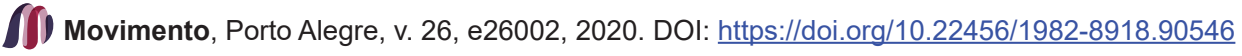


Molestie Commodo Rhoncus, Maecenas Porttitor Quam, Pellentesque Pellentesque Auctor

Continuação do quadro 1

\begin{tabular}{|c|c|c|c|c|c|c|c|c|c|c|c|}
\hline $\begin{array}{l}\text { Futebol } \\
\text { de } 5\end{array}$ & Paralímpico & Verão & Outro & Português & $\begin{array}{c}\text { Futebol de cinco para } \\
\text { deficientes visuais }\end{array}$ & $\begin{array}{c}\text { Mário Antônio de } \\
\text { Moura Simim/Célio } \\
\text { Quintão Calsavara/ } \\
\text { Bruno Victor Corrêa } \\
\text { da Silva/Gustavo } \\
\text { Ribeiro da Mota/ } \\
\text { Hélvio Feliciano } \\
\text { Moreira }\end{array}$ & $\begin{array}{c}\text { Revista Brasileira } \\
\text { de Futsal e } \\
\text { Futebol }\end{array}$ & 2015 & \begin{tabular}{|c|} 
Universidade \\
Federal do \\
Triângulo Mineiro/ \\
Academia \\
Paralímpica \\
Brasileira/ \\
Faculdade \\
Pitágoras/Centro \\
Universitário de \\
Belo Horizonte \\
\end{tabular} & $\begin{array}{l}\text { Programa de Pós- } \\
\text { Graduação em } \\
\text { Educação Física } \\
\text { da Universidade } \\
\text { Federal do } \\
\text { Triângulo Mineiro }\end{array}$ & $\begin{array}{c}\text { Não } \\
\text { informado }\end{array}$ \\
\hline Futebol & Olímpico & Verão & Biodinâmica & Português & $\begin{array}{c}\text { Futebol e a construção } \\
\text { da imagem de } \\
\text { treinadores pela mídia: } \\
\text { um estudo a partir das } \\
\text { notícias de um site de } \\
\text { grande visitação na } \\
\text { web }\end{array}$ & \begin{tabular}{|c} 
Roberto Nascimento \\
Braga da Silva/ \\
Guilherme Augusto \\
Talamoni/Antonio \\
Carlos Tavares \\
Junior/Franz Eric \\
de Goes Cressoni/ \\
Marina Tebaldi/Flávio \\
Pajanian/André Luis \\
de Oliveira/Alexandre \\
Janotta Drigo
\end{tabular} & $\begin{array}{c}\text { Revista Brasileira } \\
\text { de Ciências do } \\
\text { Esporte }\end{array}$ & 2014 & \begin{tabular}{|c|} 
Universidade \\
Estadual Paulista/ \\
Universidade Nove \\
de Julho
\end{tabular} & $\begin{array}{c}\text { Programa de } \\
\text { Pós-Graduação } \\
\text { em Ciências da } \\
\text { Motricidade da } \\
\text { Universidade } \\
\text { Estadual Paulista } \\
\text { Júlio de Mesquita } \\
\text { Filho/Rio Claro } \\
\text { (SP) }\end{array}$ & $\begin{array}{c}\text { Não } \\
\text { informado }\end{array}$ \\
\hline
\end{tabular}

Fonte: dados da pesquisa.

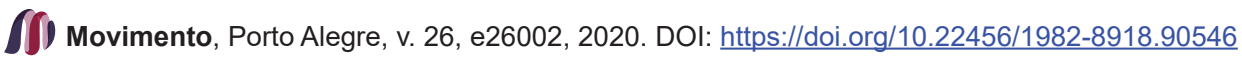




\subsection{A PRODUÇÃO DOS PROGRAMAS}

No período 2010-2016, 34 PPGEF declararam a sua produção à Capes em um ou mais anos, sendo que alguns desses programas já existiam e outros foram criados ou deixaram de existir durante esses anos. Esses programas publicaram ao todo 3.252 artigos relacionados com o esporte.

Quadro 2 - Programas que entraram no escopo do estudo

\begin{tabular}{|c|c|}
\hline SIGLA & NOME DO PROGRAMA \\
\hline PAPGEF/UPE-UFPB & $\begin{array}{l}\text { Programa de Pós-Graduação Associado em Educação Física da } \\
\text { Universidade de Pernambuco/Universidade Federal da Paraíba }\end{array}$ \\
\hline PPGCAF/EACH/USP & $\begin{array}{c}\text { Programa de Pós-Graduação em Ciências da Atividade Física da } \\
\text { Universidade de São Paulo }\end{array}$ \\
\hline PPGCAF/UNIVERSO & $\begin{array}{c}\text { Programa de Pós-Graduação em Ciências da Atividade Física da } \\
\text { Universidade Salgado de Oliveira }\end{array}$ \\
\hline PPGCE/UFMG & $\begin{array}{c}\text { Programa de Pós-Graduação em Ciências do Esporte da Universidade } \\
\text { Federal de Minas Gerais }\end{array}$ \\
\hline PPGCEE/UERJ & $\begin{array}{c}\text { Programa de Pós-Graduação em Ciências do Exercício e do Esporte da } \\
\text { Universidade do Estado do Rio de Janeiro }\end{array}$ \\
\hline PPGCM/UNESP-RC & $\begin{array}{c}\text { Programa de Pós-Graduação em Ciências da Motricidade da Universidade } \\
\text { Estadual Paulista Júlio de Mesquita Filho/Rio Claro (SP) }\end{array}$ \\
\hline PPGCMH/UDESC & $\begin{array}{c}\text { Programa de Pós-Graduação em Ciências do Movimento Humano da } \\
\text { Universidade do Estado de Santa Catarina }\end{array}$ \\
\hline PPGCMH/UFRGS & $\begin{array}{c}\text { Programa de Pós-Graduação em Ciências do Movimento Humano da } \\
\text { Universidade Federal do Rio Grande do Sul }\end{array}$ \\
\hline PPGCMH/UNICSUL & $\begin{array}{c}\text { Programa de Pós-Graduação em Ciências do Movimento Humano da } \\
\text { Universidade Cruzeiro do Sul }\end{array}$ \\
\hline PPGCMH/UNIMEP & $\begin{array}{c}\text { Programa de Pós-Graduação em Ciências do Movimento Humano da } \\
\text { Universidade Metodista de Piracicaba }\end{array}$ \\
\hline PPGEDF/UFPR & $\begin{array}{l}\text { Programa de Pós-Graduação em Educação Física da Universidade } \\
\text { Federal do Paraná }\end{array}$ \\
\hline PPGEDF/UFSM & $\begin{array}{c}\text { Programa de Pós-Graduação em Educação Física da Universidade } \\
\text { Federal de Santa Maria }\end{array}$ \\
\hline PPGEDF/USJT & $\begin{array}{l}\text { Programa de Pós-Graduação em Educação Física da Universidade São } \\
\text { Judas Tadeu }\end{array}$ \\
\hline PPGEF/FUFS & $\begin{array}{c}\text { Programa de Pós-Graduação em Educação Física da Fundação } \\
\text { Universidade Federal de Sergipe }\end{array}$ \\
\hline PPGEF/UEM-UEL & $\begin{array}{l}\text { Programa de Pós-Graduação Associado em Educação Física da } \\
\text { Universidade Estadual de Londrina/Universidade Estadual de Maringá }\end{array}$ \\
\hline PPGEF/UFES & $\begin{array}{l}\text { Programa de Pós-Graduação em Educação Física da Universidade } \\
\text { Federal do Espírito Santo }\end{array}$ \\
\hline PPGEF/UFMA & $\begin{array}{c}\text { Programa de Pós-Graduação em Educação Física da Universidade } \\
\text { Federal do Maranhão }\end{array}$ \\
\hline PPGEF/UFMT & $\begin{array}{l}\text { Programa de Pós-Graduação em Educação Física da Universidade } \\
\text { Federal do Mato Grosso }\end{array}$ \\
\hline PPGEF/UFPE & $\begin{array}{l}\text { Programa de Pós-Graduação em Educação Física da Universidade } \\
\text { Federal de Pernambuco }\end{array}$ \\
\hline PPGEF/UFPEL & $\begin{array}{l}\text { Programa de Pós-Graduação em Educação Física da Universidade } \\
\text { Federal de Pelotas }\end{array}$ \\
\hline PPGEF/UFRJ & $\begin{array}{l}\text { Programa de Pós-Graduação em Educação Física da Universidade } \\
\text { Federal do Rio de Janeiro }\end{array}$ \\
\hline
\end{tabular}


Continuação do quadro 1.

\begin{tabular}{|c|c|}
\hline PPGEF/UFRN & $\begin{array}{c}\text { Programa de Pós-Graduação em Educação Física da Universidade } \\
\text { Federal do Rio Grande do Norte }\end{array}$ \\
\hline PPGEF/UFSC & $\begin{array}{c}\text { Programa de Pós-Graduação em Educação Física da Universidade } \\
\text { Federal de Santa Catarina }\end{array}$ \\
\hline PPGEF/UFTM & $\begin{array}{c}\text { Programa de Pós-Graduação em Educação Física da Universidade } \\
\text { Federal do Triângulo Mineiro }\end{array}$ \\
\hline PPGEF/UGF & $\begin{array}{c}\text { Programa de Pós-Graduação em Educação Física da Universidade Gama } \\
\text { Filho }\end{array}$ \\
\hline PPGEF/UNB & $\begin{array}{l}\text { Programa de Pós-Graduação em Educação Física da Universidade de } \\
\text { Brasília }\end{array}$ \\
\hline PPGEF/UNIMEP & $\begin{array}{l}\text { Programa de Pós-Graduação em Educação Física da Universidade } \\
\text { Metodista de Piracicaba }\end{array}$ \\
\hline PPGEF/UNIVASF & $\begin{array}{l}\text { Programa de Pós-Graduação em Educação Física da Universidade } \\
\text { Federal do Vale do São Francisco }\end{array}$ \\
\hline PPGEFE/EEFE/USP & $\begin{array}{c}\text { Programa de Pós-Graduação em Educação Física e Esporte da } \\
\text { Universidade de São Paulo }\end{array}$ \\
\hline PPGEFE/EEFERP/USP & $\begin{array}{c}\text { Programa de Pós-Graduação em Educação Física e Esporte da } \\
\text { Universidade de São Paulo/Ribeirão Preto }\end{array}$ \\
\hline PPGEFI/UFV-UFJF & $\begin{array}{l}\text { Programa de Pós-Graduação Associado em Educação Física da } \\
\text { Universidade Federal de Viçosa/Universidade Federal de Juiz de Fora }\end{array}$ \\
\hline PPGFEF/UNICAMP & $\begin{array}{c}\text { Programa de Pós-Graduação em Educação Física da Universidade } \\
\text { Estadual de Campinas }\end{array}$ \\
\hline PPGSSEF/UCB & $\begin{array}{l}\text { Programa de Pós-Graduação em Educação Física da Universidade } \\
\text { Católica de Brasília }\end{array}$ \\
\hline PPGSSEFPS/UNOPAR & $\begin{array}{l}\text { Programa de Pós-Graduação em Exercício Físico na Promoção da Saúde } \\
\text { da Universidade Norte do Paraná }\end{array}$ \\
\hline
\end{tabular}

Fonte: dados da pesquisa.

O Gráfico 1 apresenta os PPGEF que mais produziram artigos relativos ao esporte e/ou modalidades esportivas entre os anos de 2010 a 2016.

Gráfico 1 - PPGEF que mais produziram artigos relativos ao esporte e/ou modalidades esportivas no período 2010-2016

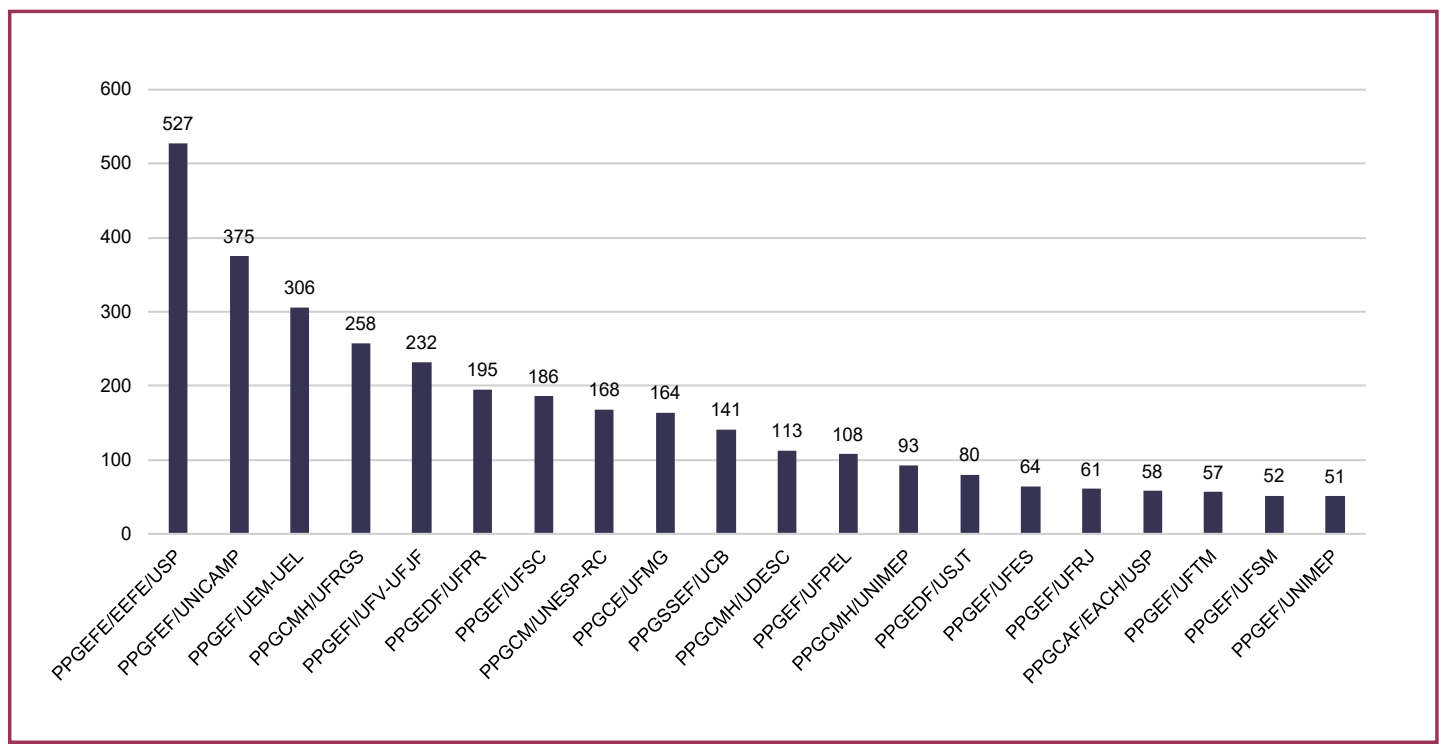

Fonte: dados da pesquisa. 
O programa que mais produziu sobre o esporte no período considerado foi o PPGEFE/EEFE/USP, com participação em 16,2\% dos artigos publicados, seguido pelo PPGFEF/UNICAMP (presente em $11,5 \%$ da produção total). O terceiro programa foi o PPGEF/UEM-UEL ( $9,4 \%$ da produção) e o quarto foi o PPGCMH/UFRGS $(7,9 \%)$. Exceto pelo PPGEF/UEM-UEL, os três outros estão entre os mais antigos PPGEF do país. Os níveis de produção desses programas estão provavelmente relacionados com fatores tais como o seu tempo de existência e número de linhas de pesquisa e de docentes dedicados ao estudo do esporte.

\subsection{AS SUBÁREAS DE CONCENTRAÇÃO DA PRODUÇÃO}

Verificamos que $70 \%$ de toda a produção se encaixa na subárea biodinâmica, seguida das subáreas sociocultural $(21 \%)$, pedagógica $(8 \%)$ e "outras" $(3 \%)$, na qual classificamos artigos que não se enquadram em nenhuma das três primeiras categorias sistematizadas por Manoel e Carvalho (2011). Este resultado vai ao encontro dos resultados de outros estudos que também verificaram a hegemonia da subárea biodinâmica na produção de conhecimentos no campo da EF (CASTRO et al., 2017; MANOEL; CARVALHO, 2011; ROSA; LETA, 2011) e do esporte e/ou modalidades esportivas (GONÇALVES et al., 2017; MOREIRA et al., 2017; PÉREZGUTIÉRREZ et al., 2017; ROJO et al., 2018; SOUZA; SILVA; MOREIRA, 2016)4.

Gráfico 2 - Produção de artigos sobre o esporte por subárea

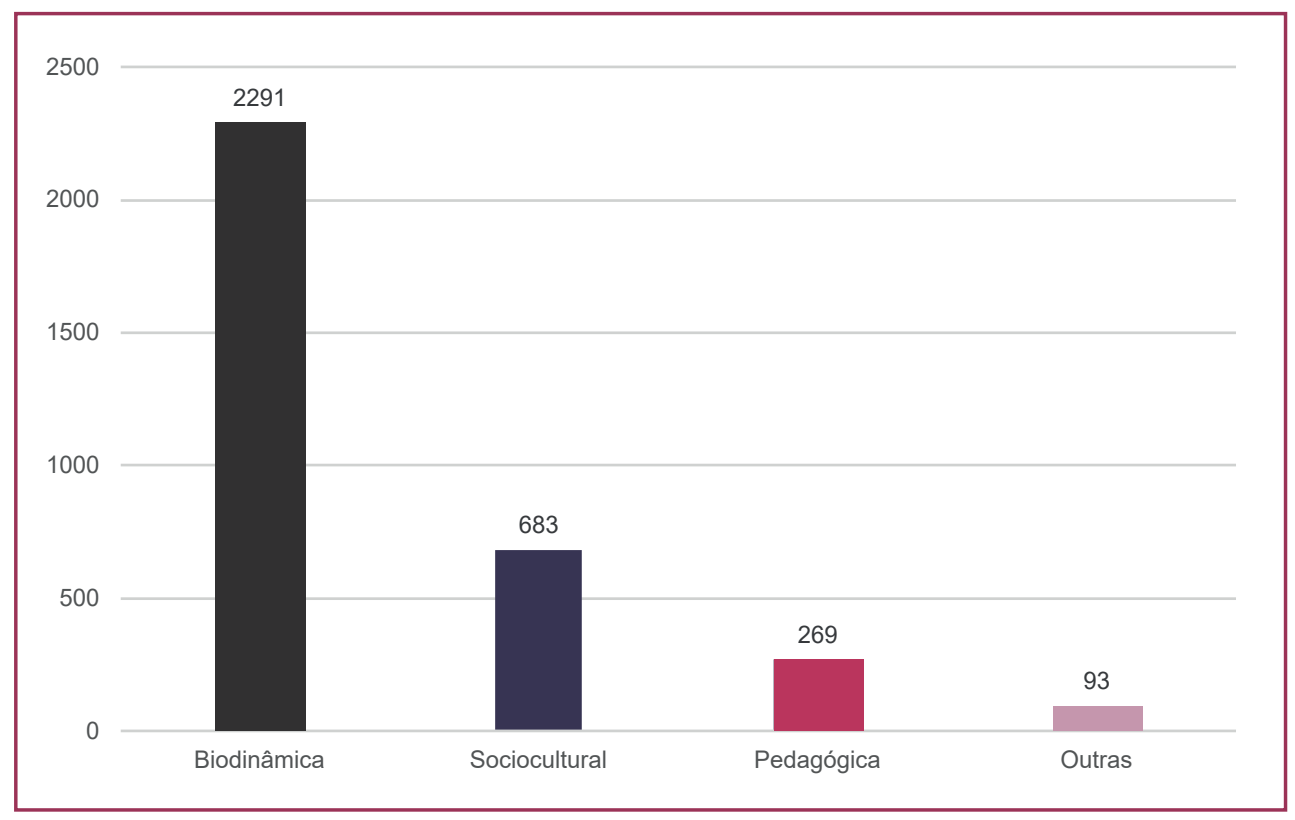

Fonte: dados da pesquisa

Se computarmos a produção de todos os programas, os que mais publicaram sobre o esporte na subárea biodinâmica foram: PPGEFE/EEFE/USP (presente em $15,8 \%$ de toda a produção na área), PPGEF/UEM-UEL (9,2\%) e PPGFEF/UNICAMP $(8,9 \%)$. Os que se sobressaíram na subárea sociocultural foram: PPGEDF/UFPR (16,5\%), PPGCMH/UFRGS (5,2\%) e PPGFEF/UNICAMP (10,1\%). Já na subárea pedagógica foram: PPGFEF/UNICAMP (18,3\%), PPGEFE/EEFE/USP (13,8\%) e 
PPGEF/UEM-UEL (7,9\%). Considerando o relatório de avaliação dos PPG relativo ao quadriênio 2013-2016 (CAPES, 2016), o único programa da área da EF nota 7 (PPGEFE/EEFE/USP) e dois (PPGCMH/UFRGS e PPGEF/UFSC) dos três programas que entraram no escopo desta pesquisa e que hoje são nota 6 , têm maior parte da sua produção atrelada à biodinâmica.

Gráfico 3 - Programas que mais produziram por subárea.

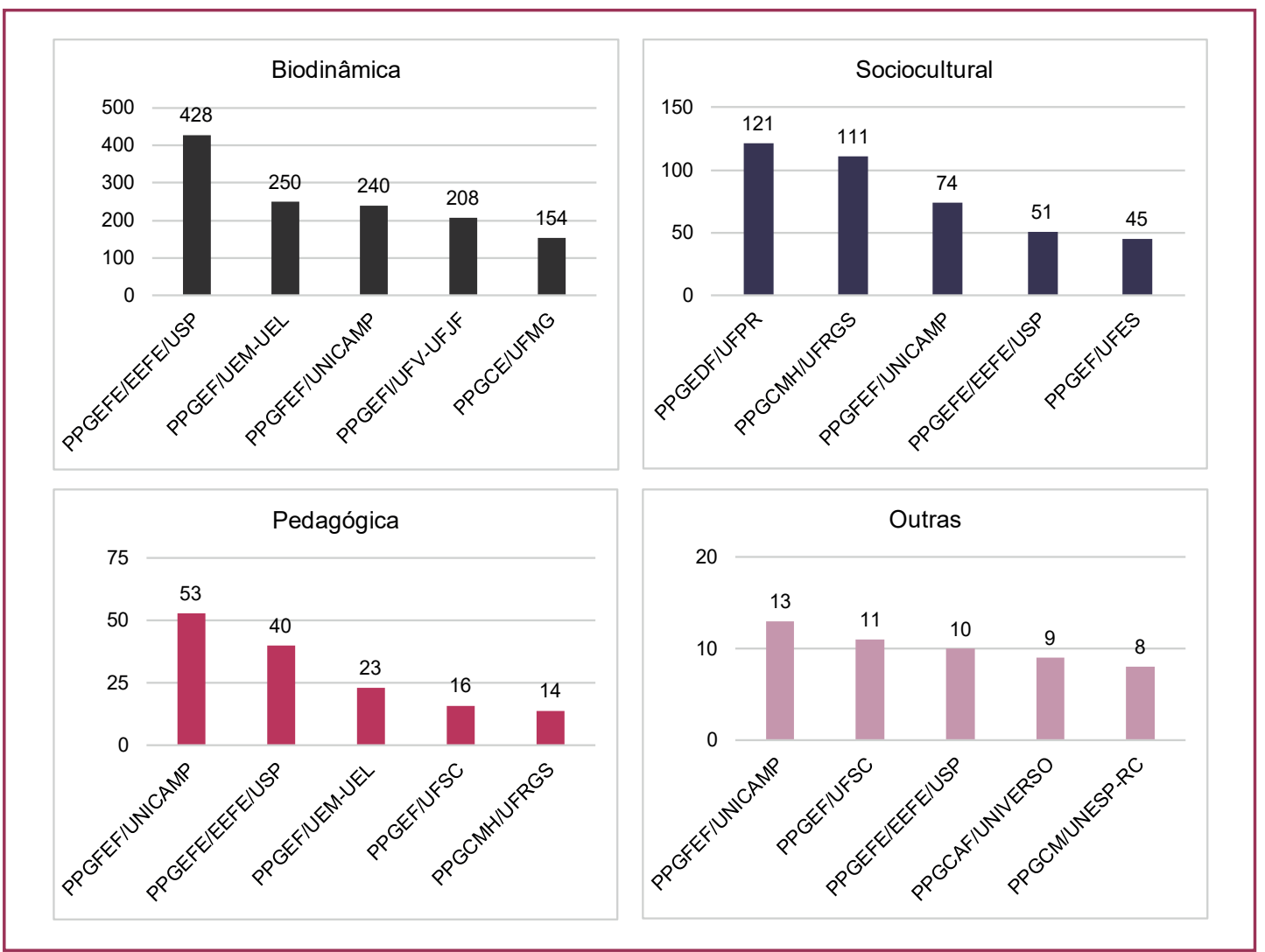

Fonte: dados da pesquisa

$\mathrm{Na}$ Tabela 1 apresentamos dados relativos ao número de produções por programa e por subárea, bem como o número de publicações em português e língua estrangeira, considerando o número total de artigos de cada programa.

Tabela 1 - Produção relativa ao esporte de cada programa considerando o número total de artigos, subáreas de concentração e idioma.

\begin{tabular}{|c|c|c|c|c|c|c|c|}
\hline \multirow[b]{2}{*}{ PROGRAMA } & \multirow[b]{2}{*}{$\begin{array}{l}\text { TOTAL DE } \\
\text { ARTIGOS }\end{array}$} & \multicolumn{4}{|c|}{ ÁREAS } & \multicolumn{2}{|c|}{ IDIOMA } \\
\hline & & 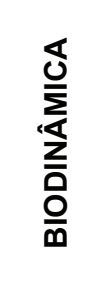 & 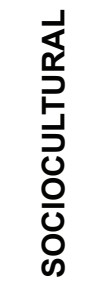 & 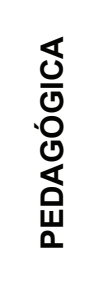 & 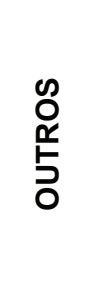 & 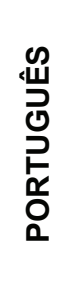 & 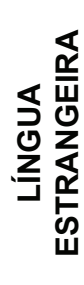 \\
\hline \multirow{2}{*}{ PPGEFE/EEFE/USP } & \multirow{2}{*}{527} & 428 & 51 & 40 & 11 & \multirow{2}{*}{197} & \multirow{2}{*}{339} \\
\hline & & $80,8 \%$ & $9,6 \%$ & $7,5 \%$ & $2,1 \%$ & & \\
\hline \multirow{2}{*}{ PPGFEF/UNICAMP } & \multirow{2}{*}{375} & 240 & 74 & 53 & 13 & \multirow{2}{*}{235} & \multirow{2}{*}{144} \\
\hline & & $63,2 \%$ & $19,5 \%$ & $13,9 \%$ & $3,4 \%$ & & \\
\hline
\end{tabular}


O perfil da produção de artigos relacionados com o esporte nos Programas de Pós-Graduação em...

Continuação da tabela 1

\begin{tabular}{|c|c|c|c|c|c|c|c|}
\hline PPGAEF/UEL-UEM & 306 & $\begin{array}{c}250 \\
79,1 \%\end{array}$ & $\begin{array}{c}36 \\
11,4 \%\end{array}$ & $\begin{array}{c}23 \\
7,3 \% \\
\end{array}$ & $\begin{array}{c}7 \\
2,2 \% \\
\end{array}$ & 186 & 130 \\
\hline PPGCMH/UFRGS & 258 & $\begin{array}{c}144 \\
52,9 \%\end{array}$ & $\begin{array}{c}111 \\
40,8 \%\end{array}$ & $\begin{array}{c}14 \\
5,1 \% \\
\end{array}$ & $\begin{array}{c}3 \\
1,1 \% \\
\end{array}$ & 192 & 68 \\
\hline PPGEFI/UFV-UFJF & 232 & $\begin{array}{c}208 \\
89,3 \%\end{array}$ & $\begin{array}{c}18 \\
7,7 \%\end{array}$ & $\begin{array}{c}4 \\
1,7 \% \\
\end{array}$ & $\begin{array}{c}3 \\
1,3 \% \\
\end{array}$ & 159 & 81 \\
\hline PPGEDF/UFPR & 195 & $\begin{array}{c}75 \\
37,9 \%\end{array}$ & $\begin{array}{c}121 \\
61,1 \%\end{array}$ & $\begin{array}{c}1 \\
0,5 \% \\
\end{array}$ & $\begin{array}{c}1 \\
0,5 \%\end{array}$ & 135 & 60 \\
\hline PPGEF/UFSC & 186 & $\begin{array}{c}139 \\
71,6 \%\end{array}$ & $\begin{array}{c}27 \\
13,9 \%\end{array}$ & $\begin{array}{c}16 \\
8,2 \% \\
\end{array}$ & $\begin{array}{c}12 \\
6,2 \%\end{array}$ & 109 & 77 \\
\hline PPGCM/UNESP-RC & 168 & $\begin{array}{c}146 \\
86,9 \%\end{array}$ & $\begin{array}{c}7 \\
4,2 \% \\
\end{array}$ & $\begin{array}{c}7 \\
4,2 \% \\
\end{array}$ & $\begin{array}{c}8 \\
4,8 \%\end{array}$ & 57 & 113 \\
\hline PPGCE/UFMG & 164 & $\begin{array}{c}154 \\
90,6 \%\end{array}$ & $\begin{array}{c}2 \\
1,2 \% \\
\end{array}$ & $\begin{array}{c}10 \\
5,9 \% \\
\end{array}$ & $\begin{array}{c}4 \\
2,4 \%\end{array}$ & 86 & 79 \\
\hline PPGSSEF/UCB & 141 & $\begin{array}{c}116 \\
82,3 \%\end{array}$ & $\begin{array}{c}16 \\
11,3 \%\end{array}$ & $\begin{array}{c}5 \\
3,5 \% \\
\end{array}$ & $\begin{array}{c}4 \\
2,8 \%\end{array}$ & 71 & 76 \\
\hline PPGCMH/UDESC & 113 & $\begin{array}{c}88 \\
75,2 \% \\
\end{array}$ & $\begin{array}{c}17 \\
14,5 \%\end{array}$ & $\begin{array}{c}6 \\
5,1 \% \\
\end{array}$ & $\begin{array}{c}6 \\
5,1 \%\end{array}$ & 75 & 38 \\
\hline PPGEF/UFPEL & 108 & $\begin{array}{c}81 \\
71,7 \%\end{array}$ & $\begin{array}{c}21 \\
18,6 \%\end{array}$ & $\begin{array}{c}11 \\
9,7 \% \\
\end{array}$ & $\begin{array}{c}0 \\
0,0 \%\end{array}$ & 64 & 45 \\
\hline PPGCMH/UNIMEP & 93 & $\begin{array}{c}79 \\
83,2 \% \\
\end{array}$ & $\begin{array}{c}10 \\
10,5 \%\end{array}$ & $\begin{array}{c}5 \\
5,3 \% \\
\end{array}$ & $\begin{array}{c}1 \\
1,1 \%\end{array}$ & 44 & 50 \\
\hline PPGEDF/USJT & 80 & $\begin{array}{c}53 \\
64,6 \% \\
\end{array}$ & $\begin{array}{c}11 \\
13,4 \%\end{array}$ & $\begin{array}{c}11 \\
13,4 \%\end{array}$ & $\begin{array}{c}7 \\
8,5 \%\end{array}$ & 63 & 18 \\
\hline PPGEF/UFES & 64 & $\begin{array}{c}14 \\
20,6 \% \\
\end{array}$ & $\begin{array}{c}45 \\
66,2 \%\end{array}$ & $\begin{array}{c}9 \\
13,2 \%\end{array}$ & $\begin{array}{c}0 \\
0,0 \%\end{array}$ & 55 & 10 \\
\hline PPGEF/UFRJ & 61 & $\begin{array}{c}48 \\
75,0 \%\end{array}$ & $\begin{array}{c}13 \\
20,3 \%\end{array}$ & $\begin{array}{c}3 \\
4,7 \% \\
\end{array}$ & $\begin{array}{c}0 \\
0,0 \%\end{array}$ & 28 & 34 \\
\hline PPGCAF/EACH/USP & 58 & $\begin{array}{c}42 \\
71,2 \% \\
\end{array}$ & $\begin{array}{c}16 \\
27,1 \%\end{array}$ & $\begin{array}{c}0 \\
0,0 \% \\
\end{array}$ & $\begin{array}{c}1 \\
1,7 \%\end{array}$ & 25 & 33 \\
\hline PPGEF/UFTM & 57 & $\begin{array}{c}39 \\
66,1 \%\end{array}$ & $\begin{array}{c}5 \\
8,5 \%\end{array}$ & $\begin{array}{c}12 \\
20,3 \%\end{array}$ & $\begin{array}{c}3 \\
5,1 \%\end{array}$ & 37 & 21 \\
\hline PPGEDF/UFSM & 52 & $\begin{array}{c}37 \\
68,5 \%\end{array}$ & $\begin{array}{c}8 \\
14,8 \%\end{array}$ & $\begin{array}{c}9 \\
16,7 \%\end{array}$ & $\begin{array}{c}0 \\
0,0 \%\end{array}$ & 31 & 21 \\
\hline PPGEF/UNIMEP & 51 & $\begin{array}{c}41 \\
74,5 \% \\
\end{array}$ & $\begin{array}{c}9 \\
16,4 \% \\
\end{array}$ & $\begin{array}{c}5 \\
9,1 \% \\
\end{array}$ & $\begin{array}{c}0 \\
0,0 \%\end{array}$ & 39 & 14 \\
\hline PPGEF/UGF & 48 & $\begin{array}{c}15 \\
27,8 \%\end{array}$ & $\begin{array}{c}28 \\
51,9 \%\end{array}$ & $\begin{array}{c}10 \\
18,5 \%\end{array}$ & $\begin{array}{c}1 \\
1,9 \%\end{array}$ & 38 & 10 \\
\hline PPGEF/FUFS & 48 & $\begin{array}{c}44 \\
84,6 \% \\
\end{array}$ & $\begin{array}{c}4 \\
7,7 \% \\
\end{array}$ & $\begin{array}{c}2 \\
3,8 \% \\
\end{array}$ & $\begin{array}{c}2 \\
3,8 \% \\
\end{array}$ & 21 & 30 \\
\hline PPGEF/UFRN & 48 & $\begin{array}{c}37 \\
75,5 \%\end{array}$ & $\begin{array}{c}4 \\
8,2 \% \\
\end{array}$ & $\begin{array}{c}5 \\
10,2 \%\end{array}$ & $\begin{array}{c}3 \\
6,1 \%\end{array}$ & 29 & 20 \\
\hline PPGEF/UNB & 48 & $\begin{array}{c}20 \\
40,8 \% \\
\end{array}$ & $\begin{array}{c}27 \\
55,1 \% \\
\end{array}$ & $\begin{array}{c}2 \\
4,1 \% \\
\end{array}$ & $\begin{array}{c}0 \\
0,0 \% \\
\end{array}$ & 37 & 13 \\
\hline PAPGEF/UPE-UFPB & 48 & $\begin{array}{c}29 \\
60,4 \%\end{array}$ & $\begin{array}{c}16 \\
33,3 \%\end{array}$ & $\begin{array}{c}3 \\
6,3 \%\end{array}$ & $\begin{array}{c}0 \\
0,0 \%\end{array}$ & 31 & 19 \\
\hline PPGCAF/UNIVERSO & 46 & $\begin{array}{c}15 \\
32,6 \%\end{array}$ & $\begin{array}{c}18 \\
39,1 \%\end{array}$ & $\begin{array}{c}4 \\
8,7 \%\end{array}$ & $\begin{array}{c}9 \\
19,6 \%\end{array}$ & 34 & 12 \\
\hline PPGEF/UFMT & 30 & $\begin{array}{c}17 \\
54,8 \%\end{array}$ & $\begin{array}{c}4 \\
12,9 \%\end{array}$ & $\begin{array}{c}9 \\
29,0 \%\end{array}$ & $\begin{array}{c}1 \\
3,2 \% \\
\end{array}$ & 25 & 5 \\
\hline
\end{tabular}




\begin{tabular}{|c|c|c|c|c|c|c|c|}
\hline PPGEF/UNIVASF & 28 & $\begin{array}{c}23 \\
76,7 \%\end{array}$ & $\begin{array}{c}6 \\
20,0 \%\end{array}$ & $\begin{array}{c}0 \\
0,0 \%\end{array}$ & $\begin{array}{c}1 \\
3,3 \%\end{array}$ & 14 & 15 \\
\hline PPGEFE/EEFERP/USP & 29 & $\begin{array}{c}22 \\
75,9 \% \\
\end{array}$ & $\begin{array}{c}1 \\
3,4 \% \\
\end{array}$ & $\begin{array}{c}5 \\
17,2 \% \\
\end{array}$ & $\begin{array}{c}1 \\
3,4 \% \\
\end{array}$ & 10 & 19 \\
\hline PPGSSEFPS/UNOPAR & 21 & $\begin{array}{c}18 \\
85,7 \%\end{array}$ & $\begin{array}{c}1 \\
4,8 \%\end{array}$ & $\begin{array}{c}2 \\
9,5 \%\end{array}$ & $\begin{array}{c}0 \\
0,0 \%\end{array}$ & 13 & 8 \\
\hline PPGCEE/UERJ & 20 & $\begin{array}{c}14 \\
70,0 \%\end{array}$ & $\begin{array}{c}4 \\
20,0 \%\end{array}$ & $\begin{array}{c}2 \\
10,0 \%\end{array}$ & $\begin{array}{c}0 \\
0,0 \%\end{array}$ & 8 & 12 \\
\hline PPGCMH/UNICSUL & 15 & $\begin{array}{c}14 \\
93,3 \% \\
\end{array}$ & $\begin{array}{c}0 \\
0,0 \%\end{array}$ & $\begin{array}{c}1 \\
6,7 \%\end{array}$ & $\begin{array}{c}0 \\
0,0 \%\end{array}$ & 3 & 13 \\
\hline PPGEF/UFPE & 10 & $\begin{array}{c}9 \\
90,0 \%\end{array}$ & $\begin{array}{c}1 \\
10,0 \%\end{array}$ & $\begin{array}{c}0 \\
0,0 \%\end{array}$ & $\begin{array}{c}0 \\
0,0 \%\end{array}$ & 2 & 8 \\
\hline PPGEF/UFMA & 8 & $\begin{array}{c}7 \\
87,5 \%\end{array}$ & $\begin{array}{c}0 \\
0,0 \%\end{array}$ & $\begin{array}{c}1 \\
12,5 \%\end{array}$ & $\begin{array}{c}0 \\
0,0 \%\end{array}$ & 1 & 7 \\
\hline
\end{tabular}

Fonte: dados da pesquisa.

O número total de artigos publicados na subárea biodinâmica cresceu consideravelmente entre 2010 e 2016. Já no caso das subáreas sociocultural e pedagógica, estas não tiveram aumento significativo.

Gráfico 4 - Evolução temporal das publicações relativas ao esporte considerando as diferentes subáreas

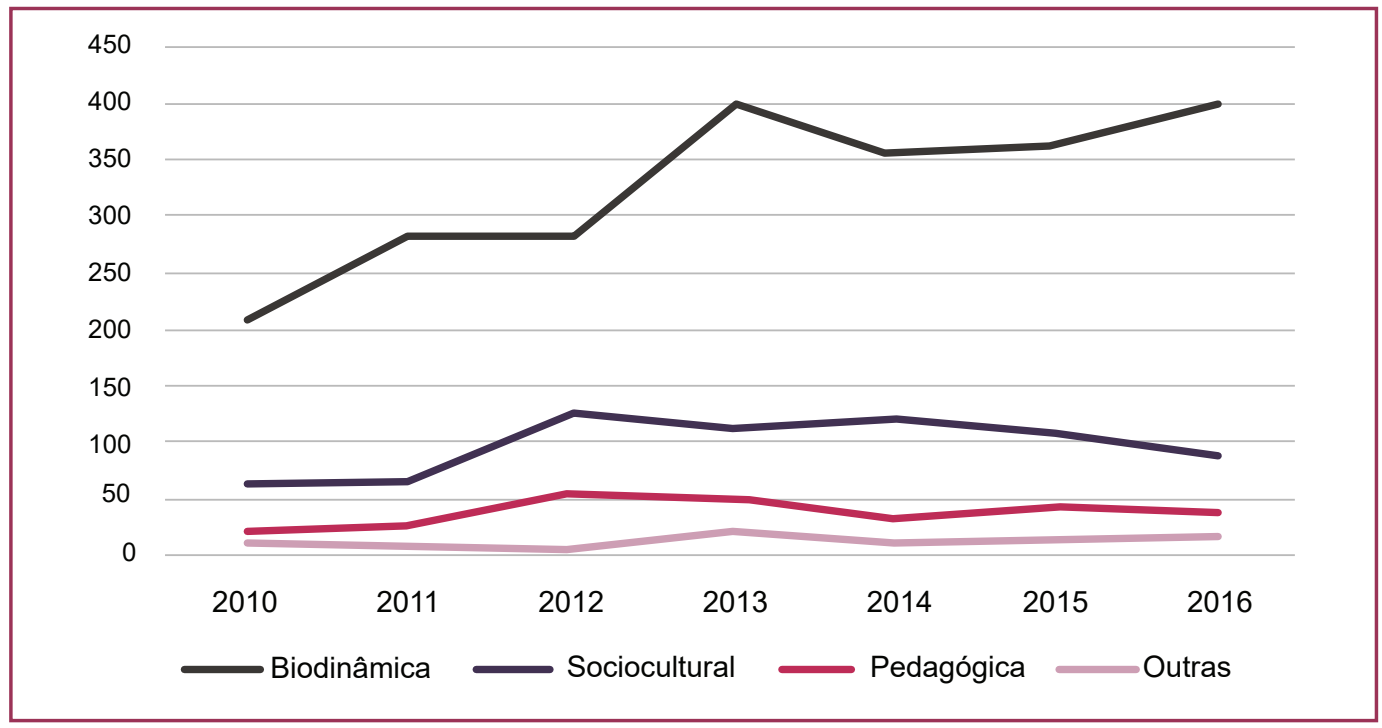

Fonte: dados da pesquisa.

Vários estudos apontam que a maior quantidade de produções na subárea biodinâmica comparada às subáreas sociocultural e pedagógica está relacionada aos critérios de avaliação dos PPGEF da Área 215 (BRACHT, 2015; CASTRO et al., 2017; CENÁRIOS..., 2015; CORRÊA; CORRÊA; RIGO, 2018; MANOEL, 2015; MANOEL; CARVALHO, 2011; RIGO; RIBEIRO; HALLAL, 2011; ROSA; LETA, 2011; SILVA; GONÇALVES-SILVA; MOREIRA, 2014; STIGGER; SILVEIRA; MYSKIW, 2015; TAVARES, 2015). Um dos itens mais valorizados é a quantidade de publicações

5 Vale ressaltar que a Fisioterapia, Terapia Ocupacional e Fonoaudiologia também fazem parte desta área e exercem influência nestes critérios. 
com maior fator de impacto $(\mathrm{FI})$ e mais bem qualificadas no Qualis (FERREIRA; MOREIRA, 2003; MANOEL; CARVALHO, 2011; CAPES, 2016). O cálculo do FI leva em consideração a quantidade de vezes que determinada revista é citada em um período de dois anos anteriores ao ano para o qual o índice está sendo medido (GARFIELD, 1997).

Algumas implicações desse critério são que periódicos cujo escopo abrange áreas com ritmo acelerado de renovação do conhecimento acabam sendo citados intensivamente por um período curto após sua publicação, favorecendo o seu FI. Ao contrário, periódicos que publicam em áreas que necessitam de um tempo maior para atingir a mesma contagem de citações obtêm um FI menor (WALLIN, 2005) - este é o caso dos periódicos voltados às Ciências Sociais e Humanas, cujas publicações tendem a usar referenciais teóricos mais clássicos (GARFIELD, 1997). Pesquisas com caráter predominantemente regional (característica das produções das Ciências Sociais e Humanas) acabam não servindo como referência para publicações em âmbito internacional (WALLIN, 2005), o que limita a possibilidade de os periódicos dedicados a essas áreas atingirem maior $\mathrm{Fl}$.

Áreas de conhecimento com maior número de periódicos dedicados tendem a publicar um maior volume de artigos, o que pode resultar em maior possibilidade de serem citados (GARFIELD, 1997; PINTO; ANDRADE, 1999). Conforme Manoel (2015), que realizou um levantamento dos periódicos indexados no WebQualis da Área 21 em 2014, 70\% dos periódicos com estrato A1 dedicavam-se às áreas da Medicina e Ciências Biológicas. Essas áreas eram também majoritárias nos estratos A2 e B1. De acordo com Corrêa, Corrêa e Rigo (2018), que analisaram os periódicos estratificados no Qualis Periódicos do quadriênio 2013-2016, nesse período a subárea biodinâmica foi ainda mais privilegiada: $94,1 \%$ dos periódicos no estrato $A 1$, $91,6 \%$ no estrato A2 e $90,2 \%$ no estrato B1 se dedicaram a ela.

Dada a dificuldade de publicação de artigos das subáreas sociocultural e pedagógica em periódicos com estratos mais altos na Área 21, vários pesquisadores têm publicado os seus trabalhos em periódicos de outros campos de conhecimento (ex. Educação, História, Sociologia). No entanto, no processo de avaliação da Área 21, as suas publicações tendem a cair de estrato. Muitos pesquisadores têm também migrado para outros PPG (RIGO; RIBEIRO; HALLAL, 2011), inserindo-se em áreas como a Educação e a História (CENÁRIOS..., 2015). Esse fenômeno vem enfraquecendo as subáreas sociocultural e pedagógica dentro dos PPGEF, e consequentemente, publicações nestas subáreas.

Outro fator relacionado à predominância da subárea biodinâmica se relaciona com o perfil dos docentes dos PPGEF. Rigo, Ribeiro e Hallal (2011) analisaram a composição do quadro de professores de 21 PPGEF entre os anos de 2007 a 2011 e verificaram que em $80 \%$ deles havia mais professores vinculados às Ciências Biológicas e da Saúde do que às Ciências Sociais e Humanas. Corrêa, Corrêa e Rigo (2018) fizeram levantamento similar em 2017 e concluíram que 71,77\% estão lotados na biodinâmica, $24,77 \%$ na sociocultural e pedagógica e 3,45\% nestas duas subáreas conjuntamente. Ao compararem os dados de sua pesquisa com o estudo de Rigo, Ribeiro e Hallal (2011, p. 4), eles verificaram que, de 2010 a 2017, o crescimento entre as subáreas foi desproporcional: "[...] enquanto, juntas, as subáreas sociocultural e pedagógica passaram de 142 (em 2010) para 165 pesquisadores credenciados em 2017, a subárea biodinâmica passou de 260 para 478". 
Ainda outro fator relacionado com a hegemonia da biodinâmica é o financiamento das pesquisas. O Gráfico 5 ilustra como este ficou distribuído de acordo com as subáreas de conhecimento durante o período considerado.

Gráfico 5 - Financiamento nas diferentes subáreas

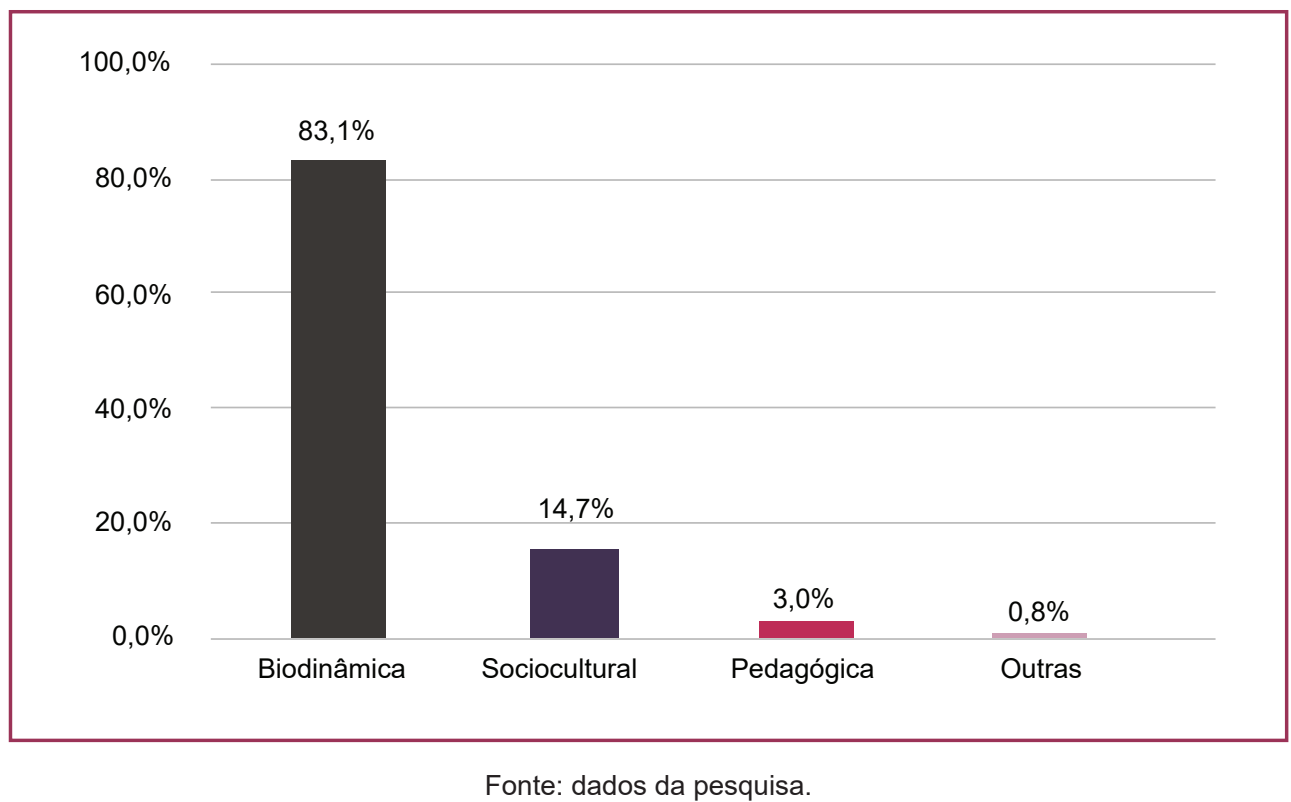

Constatamos que, dos $19 \%$ dos artigos que declararam suas fontes de financiamento, $83,1 \%$ se encaixam na biodinâmica, $14,7 \%$ na sociocultural e $3,0 \%$ na pedagógica. Embora esses dados possam estar enviesados, pois faltam informações sobre financiamento na maior parte das publicações, eles demonstram uma tendência maior de financiamento para a subárea biodinâmica.

\subsection{OS IDIOMAS DAS PUBLICAÇÕES}

Conforme se pode verificar no Gráfico 6, se comparados os anos de 2010 a 2016, houve um crescimento da produção sobre o esporte, com uma queda em 2014. Talvez isso tenha ocorrido porque os autores passaram a priorizar publicações em periódicos com maior fator de impacto, o que pode ter afetado a quantidade de produções. A produção em língua estrangeira expandiu-se consideravelmente a partir de 2012, ultrapassando o número total de produções em português em 2016. Enquanto em 2010 a produção em língua estrangeira correspondia a $28 \%$ da produção, em 2016 passou a corresponder a 60\%. Esses dados contrastam com os achados de Rosa e Leta (2011), que analisaram os idiomas das publicações dos PPGEF entre 2001 e 2003 - na época, $80 \%$ de toda a produção era em português.

Existe uma tendência mundial de internacionalização da produção, especialmente em inglês (ÁLVARES, 2016). Seguindo essa tendência, as avaliações dos PPG no Brasil têm valorizado cada vez mais esse tipo de produção (RIGO; RIBEIRO; HALLAL, 2011), motivando a produção em língua estrangeira (STIGGER; SILVEIRA; MYSKIW, 2015). Segundo a Capes (2016), publicações em inglês potencializam a visibilidade das produções e a possibilidade de novas parcerias internacionais, o que pode alavancar e qualificar a produção científica brasileira. 
Gráfico 6 - Evolução das publicações de acordo com o idioma

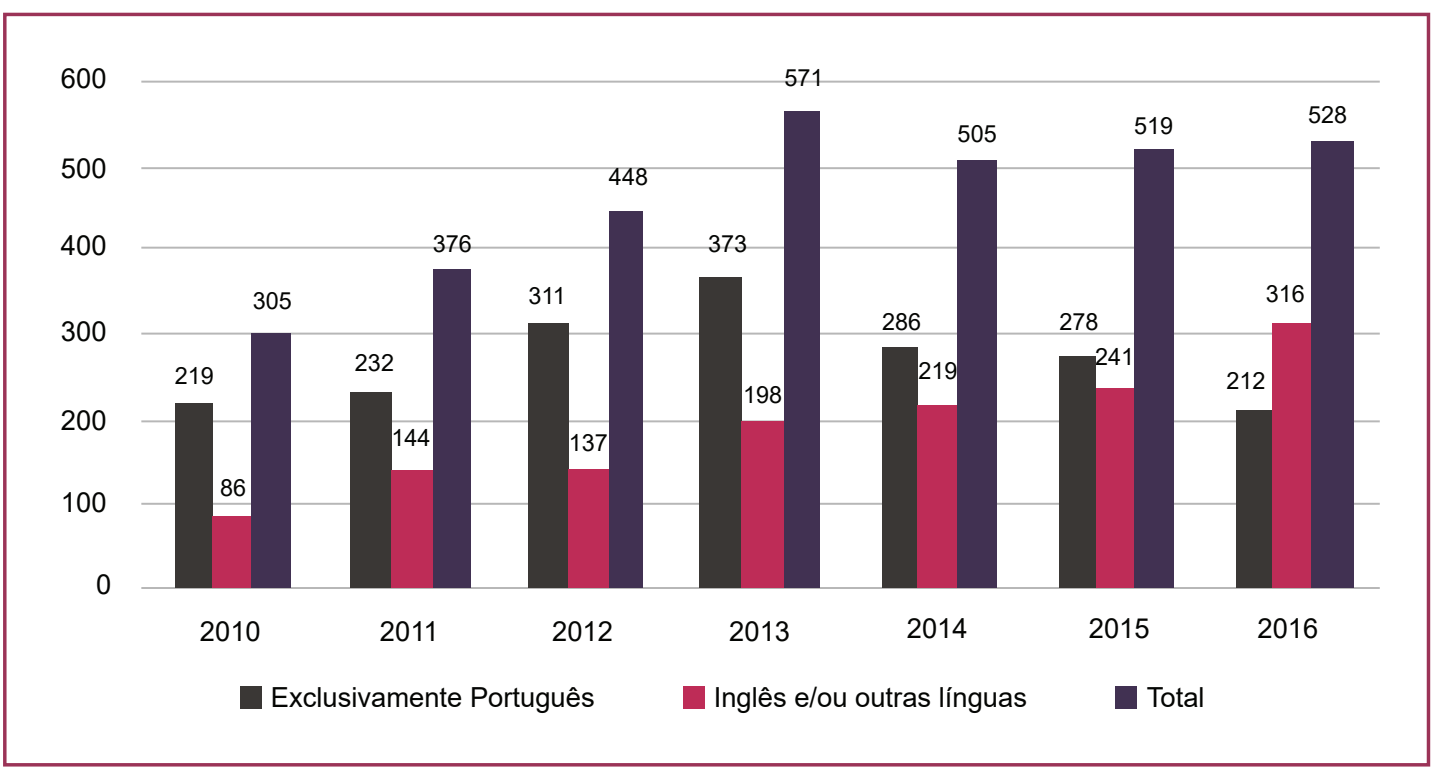

Fonte: dados da pesquisa.

Conforme se pode observar no Gráfico 7, as subáreas sociocultural, pedagógica e "outras" vêm crescendo em termos de publicações em língua estrangeira. Esse crescimento, no entanto, ainda é tímido quando comparado à produção total em língua estrangeira da subárea biodinâmica, que já desde 2013/2014 tem a maior parte de sua produção internacionalizada.

Gráfico 7 - Produção em português e outras línguas nas diferentes subáreas do conhecimento

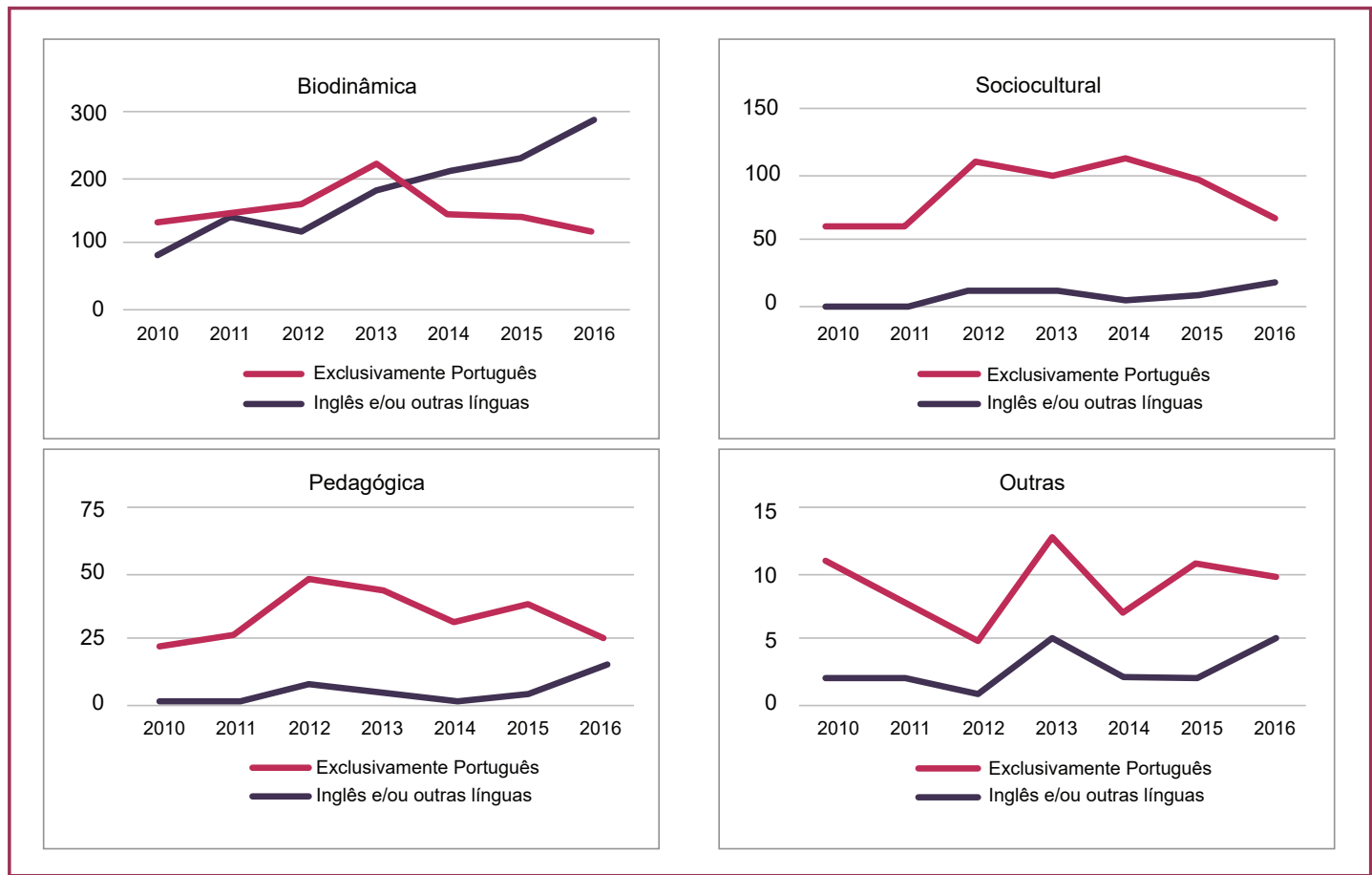

Fonte: dados da pesquisa

Amaior internacionalização da produção na subárea biodinâmica possivelmente está associada com o fato de que esta trabalha com temas mais universais do que os 
tratados pelas subáreas sociocultural e pedagógica. Nestas, os resultados tendem a ter uma aplicação mais local (CENÁRIOS..., 2015; MANOEL; CARVALHO, 2011). Por exemplo, a metodologia de uma pesquisa que investiga os efeitos da atividade física para perda de peso pode se aplicar a pessoas vivendo em diferentes partes do planeta. Já um estudo sobre os significados da participação de crianças em um projeto social no interior do Ceará dificilmente seria aplicado em contextos que não se aproximam do pesquisado. Consequentemente, trabalhos nestas subáreas, em muitos casos, não se fazem atrativos para publicação em revistas internacionais (KERR-PONTES et al., 2005; RIGO; RIBEIRO; HALLAL, 2011; RODRIGUES, 2011).

Alguns programas produziram mais sobre o tema esporte em língua estrangeira do que em português (Tabela 1). São eles: PPGEFE/EEFE/USP, PPGCM/ UNESP-RC, PPGSSEF/UCB, PPGCMH/UNIMEP, PPGEF/UFRJ, PPGCAF/EACH/ USP, PPGEF/FUFS, PPGEF/UNIVASF, PPGEFE/EEFERP/USP, PPGCEE/UERJ, PPGCMH/UNICSUL, PPGEF/UFPE e PPGEF/UFMA. Em todos esses programas, a maior parte da produção se encaixa na subárea biodinâmica. Se, por um lado, a produção em língua estrangeira potencializa a divulgação dos conhecimentos em diferentes países, por outro, ela dificulta o acesso aos conhecimentos produzidos por parte de brasileiros que não são proficientes em outros idiomas. Conforme reforçam Viveiros et al. (2015), os profissionais que trabalham diretamente com o esporte, especialmente os treinadores, encontram dificuldades para acessar revistas de acesso restrito e em língua estrangeira. Ou seja, eles que, teoricamente, estariam entre os principais usuários dos conhecimentos produzidos para aprimorarem o seu trabalho, muitas vezes não têm acesso a eles.

\subsection{COAUTORIAS}

De acordo com o nosso levantamento, corroborando os achados de Stigger, Silveira e Myskiw (2015), as publicações na subárea da biodinâmica têm um grau maior de autorias do que as outras subáreas. Do total de 2291 artigos produzidos na subárea biodinâmica, $58 \%$ deles ultrapassa cinco autores. Já no caso da subárea sociocultural, que teve 683 , e da subárea pedagógica, com 269 artigos, estas tiveram respectivamente $76,6 \%$ e $68,5 \%$ da produção desenvolvida por apenas dois, três ou quatro autores. 
Gráfico 8 - Quantidade de autores por artigos nas diferentes subáreas de conhecimento considerando toda a produção sobre esporte no período 2010-2016

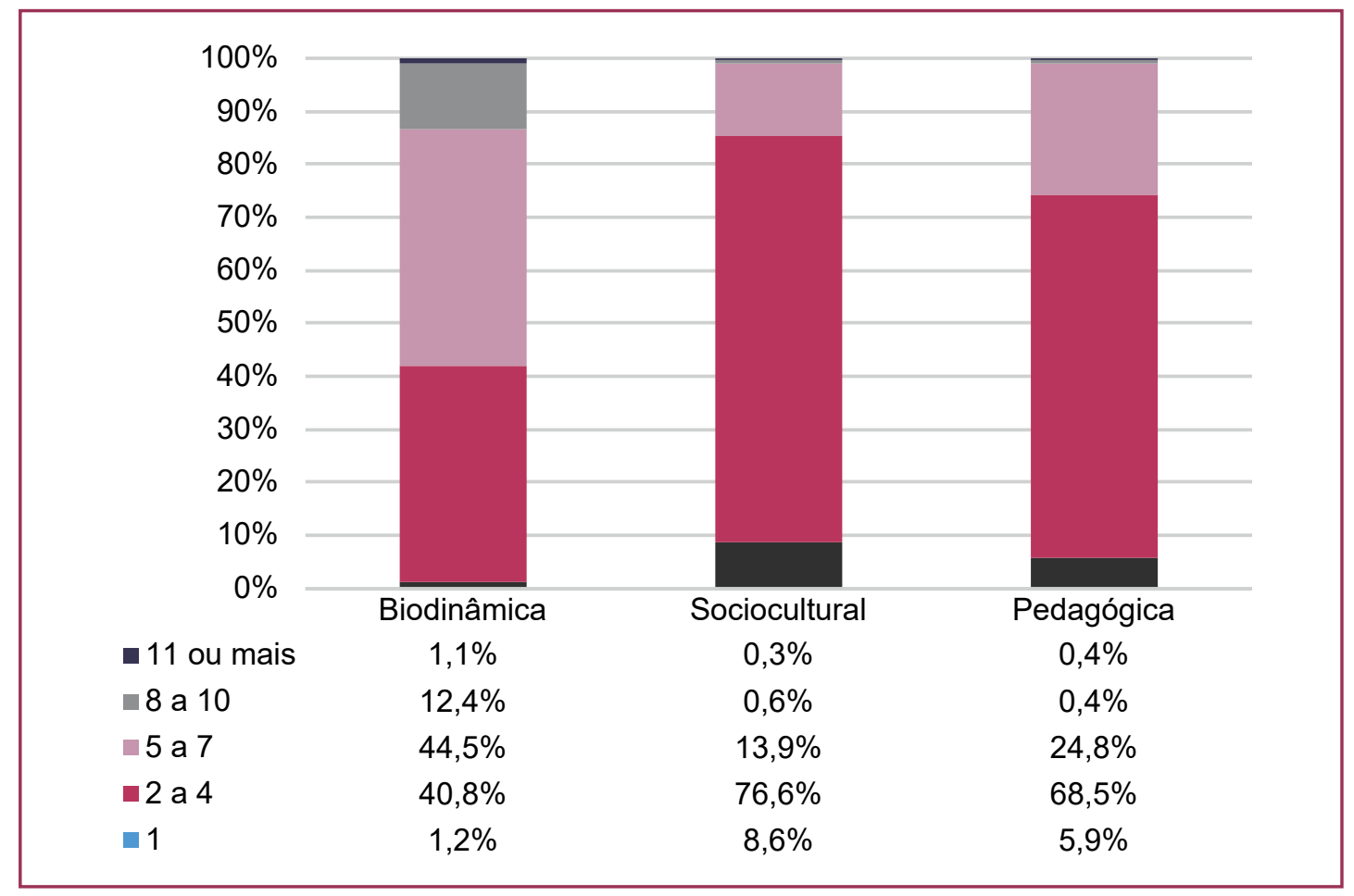

Fonte: dados da pesquisa

O processo de produção em sistema de parcerias potencializa o número de publicações por pesquisador. Ou seja, na medida em que eles colaboram em suas respectivas pesquisas, eles aumentam o número total de artigos por eles publicados (LAZZAROTTI FILHO et al., 2012; RODRIGUES, 2011; STIGGER; SILVEIRA; MYSKIW, 2015). O fato de as pesquisas desenvolvidas na subárea biodinâmica serem mais facilmente replicáveis e terem um caráter mais universal facilita a produção de estudos em colaboração com outros autores e alavanca a produção desta subárea. O mesmo não se aplica às subáreas sociocultural e pedagógica, uma vez que os conhecimentos por elas gerados tendem a ser circunscritos a determinados meios sociais e culturais (CENÁRIOS..., 2015). Também nessas subáreas existe a dificuldade de se formar grupos de pesquisa uma vez que, conforme discutimos anteriormente, existe um número menor de docentes e discentes quando comparado às linhas de pesquisa ligadas às Ciências Biológicas e da Saúde. A despeito dessas dificuldades, os pesquisadores dessas subáreas vêm buscando se adaptar ao sistema de avaliação em curso (RODRIGUES, 2011; STIGGER; SILVEIRA; MYSKIW, 2015). Os nossos dados revelam que, entre 2015 e 2016, o número de coautorias nessas subáreas teve um crescimento maior do que na biodinâmica. 
Gráfico 9 - Média de autores por artigo por subárea de conhecimento

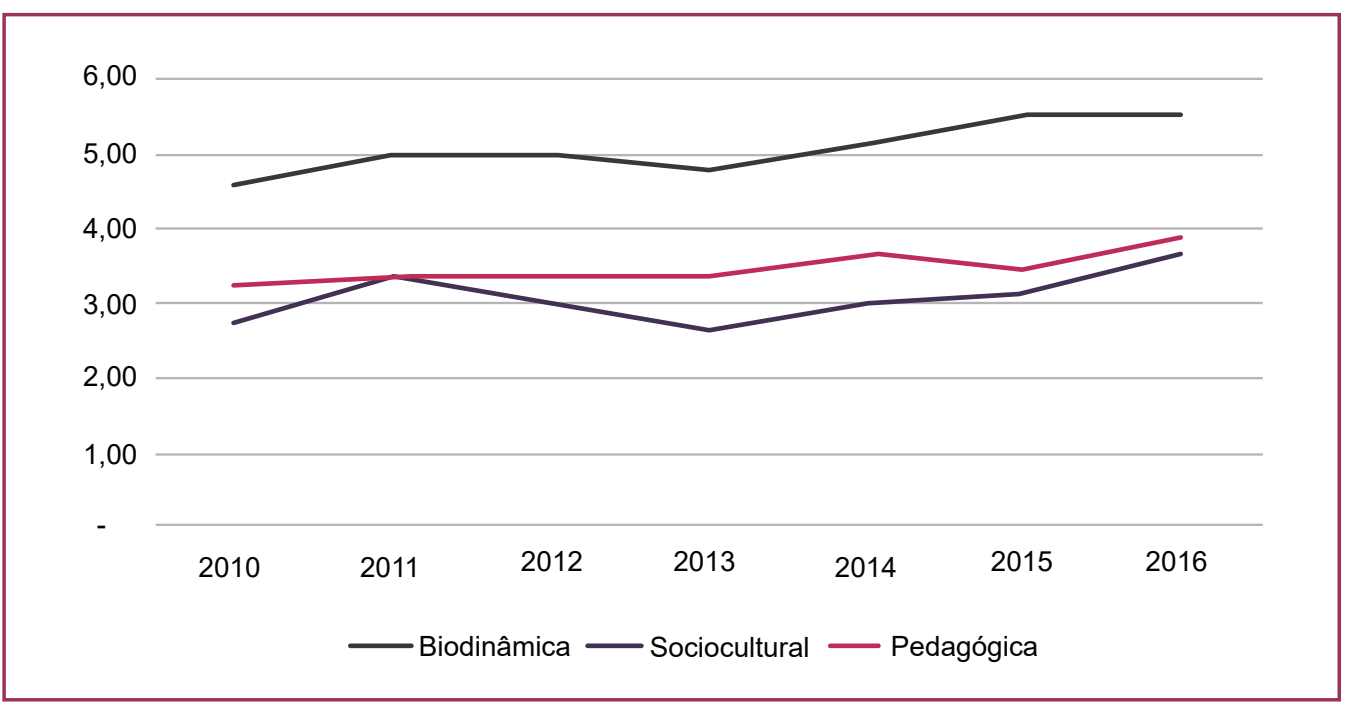

Fonte: dados da pesquisa.

A estratégia de publicação em um sistema de parcerias gera vantagens para a contagem de artigos para pesquisadores (LAZZAROTTI FILHO et al., 2012; MANOEL, 2015; RODRIGUES, 2011) e, consequentemente, para os seus programas (STIGGER; SILVEIRA; MYSKIW, 2015). Aqueles que têm maior status, estando inseridos em networkings internacionais, tendem a participar em um número maior de trabalhos, potencializando a sua produtividade (SILVA et al., 2017). Existem, no entanto, relatos de casos em que pesquisadores têm colocado o nome um dos outros em seus trabalhos, em um sistema de trocas, para aumentar a contagem de artigos por eles publicados (MANOEL, 2015). Essa denúncia precisa ser melhor investigada, uma vez que, se verdadeira, incorre em sérios problemas éticos.

\subsection{CONJUNÇÃO DE FATORES QUE SE RETROALIMENTAM: EXPLORANDO HIPÓTESES}

Aparentemente existe uma conjunção de fatores que vem retroalimentando o crescimento da subárea biodinâmica. A tradição dessa subárea no campo da Educação Física e o número de pesquisadores dedicados, as metodologias utilizadas em pesquisas na subárea biodinâmica, que por sua vez tendem a ser passíveis de replicação e generalização, e o caráter universal de grande parte dos temas tratados facilitam o desenvolvimento de parcerias entre pesquisadores. Isso, por sua vez, potencializa a publicação de um número maior de artigos em periódicos com maior fator de impacto. Isso tudo melhora o conceito dos programas e pesquisadores envolvidos. Ao serem mais bem avaliados, estes tendem a ter mais facilidade para assumir posições de decisão dentro de agências financiadoras, para participar em bancas de concursos e de corpos editoriais de revistas, para atrair vagas de mestrado e doutorado e para conseguir bolsas e financiamentos para as suas pesquisas e participação em eventos científicos e intercâmbios internacionais. Esses fatores podem estar motivando ainda mais os pesquisadores e programas a continuarem a produzir nesta perspectiva. Desta forma, a subárea vem se fortalecendo em uma espécie de espiral virtuosa.

Os trabalhos com um viés sociocultural e/ou pedagógico apresentam dificuldades como, por exemplo, um número menor de pesquisadores na subárea e a 
natureza de vários objetos de estudo que não são de interesse universal que, por sua vez, tendem a dificultar a produção em parceria, a generalização dos resultados e a internacionalização da produção. Como consequência, a avaliação de pesquisadores tende a ser mais baixa do que a dos pesquisadores da biodinâmica. Isso tende a limitar novos financiamentos para as suas pesquisas e para a participação em eventos científicos e intercâmbios internacionais. Juntos, estes e outros fatores têm dificultado a entrada e a permanência de pesquisadores destas subáreas nos PPGEF, motivando-os a migrarem para outros campos de conhecimento. Esta realidade se constitui em um círculo vicioso que tem dificultado o crescimento da produção científica destas subáreas nos PPGEF.

Na última avaliação, a Área 21 (CAPES, 2017) adotou diferentes valores de fator de impacto para estratificação da produção no sistema Qualis para as pesquisas com um viés das Ciências Sociais e Humanas visando amenizar algumas distorções do processo avaliativo. $O$ fator de impacto exigido para que estas subáreas possam se enquadrar em estratos mais altos do Qualis passou a ser mais baixo com relação ao exigido na biodinâmica. Essa mudança teve um impacto positivo na avaliação da produção dos pesquisadores das subáreas sociocultural e pedagógica. Não sabemos, contudo, se esse novo critério será suficiente para evitar que essas subáreas paulatinamente desapareçam dos PPGEF.

\section{CONCLUSÃO}

Os 34 programas analisados produziram 3.252 artigos que direta ou indiretamente discutem o esporte e modalidades com federações internacionais. A maior parte dos artigos discute temas relacionados à subárea biodinâmica (70\%), sendo que as subáreas sociocultural e pedagógica se fazem representar em uma percentagem significativamente menor (21\% e $8 \%$ ). Embora o número de produções tenha crescido entre 2010 e 2016 , houve um decréscimo na produção total de artigos a partir de 2014. Houve, no entanto, um aumento de produções em língua estrangeira. Enquanto a produção total cresceu em média $10 \%$ ao ano, a produção em inglês e/ ou outras línguas cresceu a uma taxa média de $24 \%$ ao ano ${ }^{6}$.

A produção vinculada à biodinâmica expandiu significativamente. $\mathrm{O}$ mesmo não ocorreu com as subáreas sociocultural e pedagógica. Essa realidade está aparentemente relacionada com algumas características dessas subáreas e com os critérios de avaliação dos PPGEF. Esses fatores, dentre outros que ainda não exploramos dado o escopo deste trabalho, têm levado a subárea biodinâmica a uma espécie de espiral virtuosa de crescimento, enquanto as outras duas subáreas permanecem em um círculo vicioso e limitante que vem se retroalimentando. Esse círculo precisa ser rompido para que o esporte possa ser mais bem compreendido em toda a sua complexidade.

Este trabalho tem algumas limitações, como, por exemplo, falhas nas informações prestadas nos relatórios dos programas e/ou impossibilidade de acesso a determinadas produções. Procuramos corrigir os erros e buscar as informações necessárias dentro do possível. Apesar dessas limitações, o perfil da produção sobre o esporte nos PPGEF apresentado e as hipóteses aqui levantadas oferecem

6 Taxas calculadas a partir do Compound Annual Growth Rate (CAGR). CAGR= Valor final/valor inicial^(1/qtd anos)1. 
subsídios para futuros estudos e ações em relação aos rumos da produção de conhecimento sobre o esporte no país considerando a multiplicidade de papéis que o esporte exerce em nossa sociedade.

\section{REFERÊNCIAS}

ÁLVARES, Sílvia. A ciência fala inglês? Em tempos de mudança... Nascer e Crescer Birth and growth medical journal, v. 25, n. 3, p. 133-135, 2016. Disponível em: http:// www.scielo.mec.pt/scielo.php?script=sci arttext\&pid=S0872-07542016000300001. Acesso em: 5 maio 2018.

BRACHT, Valter. Desafios e dilemas da pós-graduação em educação física. In: RECHIA, Simone et al. Dilemas e desafios da Pós-Graduação em educação física. ljuí: Ed. Unijuí, 2015. p. 109-124.

CAPES - COORDENAÇÃO DE APERFEIÇOAMENTO DE PESSOAL DE NÍVEL SUPERIOR. Documento da Área 21: Educação Física. Brasília, DF, 2016. Disponível em: http://www.capes.gov.br/images/documentos/Documentos de area 2017/21 efis docarea 2016.pdf. Acesso em: 10 abr. 2018.

CAPES - COORDENAÇÃO DE APERFEIÇOAMENTO DE PESSOAL DE NÍVEL SUPERIOR. Relatório de Avaliação 2013-2016: - Quadrienal 2017. Brasília, DF, 2017. Disponível em: http://www.capes.gov.br/images/stories/download/avaliacao/ relatorios-finais-quadrienal-2017/20122017-EDUCACAO-FISICA-quadrienal.pdf. Acesso em: 27 mar. 2018.

CASTRO, Pedro Henrique Zubcich Caiado de et al. A produção científica em Educação Física de 2001 a 2010: caminhos da construção de um campo. Movimento, v. 23, n. 3, p. 869-882, 2017. Disponível em: http://www.seer.ufrgs.br/index.php/Movimento/article/ view/64610. Acesso em: 3 abr. 2018.

CENÁRIOS de um descompasso da pós-graduação em Educação Física e demandas encaminhadas à Capes. In: FÓRUM DE PESQUISADORES DAS SUBÁREAS SOCIOCULTURAL E PEDAGÓGICA, 2015. Disponível em: http://www.cbce.org.br/ noticias-detalhe.php?id=1074. Acesso em: 30 maio 2018.

COAKLEY, Jay. Sports in Society: issues and controversies. 11. ed. New York: MacGraw- Hill, 2015.

CORREAA, Marluce Raquel Decian; CORREAA, Leandro Quadro; RIGO, Luíz Carlos. The postgraduation in the Brazilian physical education: conditions and posibilities of its sociocultural and pedagogical subareas. Revista Brasileira de Ciências do Esporte, 2018. Disponível em: https://doi.org/10.1016/j.rbce.2018.03.009 Acesso em: 04 jun. 2018.

FERREIRA, Marieta de Moraes; MOREIRA, Regina da Luz. Capes, 50 anos em depoimentos. In: FERREIRA, Marieta de Moraes; MOREIRA, Regina da Luz. CAPES 50 anos: depoimentos ao CPDOC/FGV. Brasília, DF: CAPES, 2003. p. 294-309.

GARFIELD, Eugene. Dispelling a few common myths about journal citation impacts. The Scientist, v. 11, n. 3, p. 11, 1997. Disponível em: http://www.garfield.library.upenn. edu/commentaries/tsv11\%2803\%29p11y19970203.pdf. Acesso em: 22 mar. 2018. 
GONÇALVES, Luiz Fernando et al. Mapeamento da produção do conhecimento sobre a modalidade do basquetebol nos periódicos brasileiros. Pensar a Prática, v. 20, n. 3, p. 461-475, 2017. Disponível em: https://www.revistas.ufg.br/fef/article/view/41812. Acesso em: 26 maio 2018.

JOB, Ivone. Análise bibliométrica das teses de uma comunidade científica em educação física com uso do método indiciário. Revista Brasileira de Ciências do Esporte, v. 28, n. 1, p. 201-216, 2006. Disponível em: http://revista.cbce.org.br/index. php/RBCE/article/view/47/0. Acesso em: 29 maio 2018.

KERR-PONTES, Ligia Regina Sansigolo et al. Uma reflexão sobre o processo de avaliação das pós-graduações brasileiras com ênfase na área de saúde coletiva. Physis: Revista de Saúde Coletiva, v. 15, n. 1, p. 83-94, 2005. Disponível em: http:// www.scielo.br/scielo.php?pid=S0103-73312005000100005\&script=sci abstract\&tlng=pt. Acesso em: 26 maio 2018.

LAZZAROTTI FILHO, Ari et al. Modus operandi da produção científica da educação física: uma análise das revistas e suas veiculações. Revista da Educação Física/ UEM, v. 23, n. 1, p. 1-14, 2012. Disponível em: http://www.periodicos.uem.br/ojs/index. php/RevEducFis/article/view/12551. Acesso em: 18 maio 2018.

MANOEL, Edison De Jesus. Produtivismo e ética na pesquisa em educação física: leituras, um conto e alguns casos. In: RECHIA, Simone et al. Dilemas e desafios da Pós-Graduação em educação física. Ijuí: Ed. Unijuí, 2015. p. 235-282.

MANOEL, Edison De Jesus; CARVALHO, Yara Maria De. Pós-graduação na educação física brasileira: a atração (fatal) para a biodinâmica. Educação e Pesquisa, v. 37, n. 2, p. 389-406, 2011. Disponível em: http://www.scielo.br/scielo.php?pid=S151797022011000200012\&script=sci abstract\&tIng=pt. Acesso em: 15 mar. 2018.

MOREIRA, Tatiana Sviesk et al. O perfil da produção científica em língua portuguesa sobre o voleibol. Motrivivência, v. 29, n. 51, p. 119-135, 2017. Disponível em: https:// periodicos.ufsc.br/index.php/motrivivencia/article/view/2175-8042.2017v29n51p119. Acesso em: 8 jun. 2018.

PÉREZ-GUTIÉRREZ, Mikel et al. Taekwondo scientific production published in the Web of Science (1988-2016): Collaboration and topics. Movimento, v. 23, n. 4, p. 1325-1340, 2017. Disponível em: https://repositorio.unican.es/xmlui/handle/10902/12953. Acesso em: 8 jun. 2018.

PINTO, Angelo da Cunha; ANDRADE, Jailson Bittencourt de. Fator de impacto de revistas científicas: qual o significado deste parâmetro? Química Nova, v. 22, n. 3, 1999. Disponível em: http://www.scielo.br/pdf/qn/v22n3/1101.pdf. Acesso em: $21 \mathrm{fev}$. 2019.

RIGO, Luis Carlos; RIBEIRO, Gabriela M.; HALLAL, Pedro C. Unidade na diversidade: desafios para a Educação Física no século XXI. Revista Brasileira de Atividade Física \& Saúde, v. 16, n. 4, p. 339-345, 2011. Disponível em: http://www.pgedf.ufpr.br/ downloads/Artigos\%20PS\%20Mest\%202016/ELS/marcelo/631-1159-1-PB.pdf. Acesso em: 22 mar. 2018.

RODRIGUES, Luiz Oswaldo Carneiro. Publicar mais, ou melhor? O tamanduá Olímpico. Psicologia USP, v. 22, n. 2, p. 457-472, 2011. Disponível em: http://www. revistas.usp.br/psicousp/article/view/42092. Acesso em: 23 mar. 2018.

ROJO, Jeferson Roberto et al. O mapeamento da produção do conhecimento sobre a corrida de rua em periódicos brasileiros. Corpoconsciência, v. 22, n. 1, p. 88-100, 
2018. Disponível em: http://periodicoscientificos.ufmt.br/ojs/index.php/corpoconsciencia/ article/view/6246. Acesso em: 29 maio 2018.

ROSA, Suely; LETA, Jacqueline. Tendências atuais da pesquisa brasileira em Educação Física. Parte 2: a heterogeneidade epistemológica nos programas de pós-graduação. Revista Brasileira de Ciências do Esporte, v. 25, n. 1, p. 7-18, 2011. Disponível em: $\underline{\text { http: } / / w w w . s c i e l o . b r / s c i e l o . p h p ? s c r i p t=s c i ~ a r t t e x t \& p i d=S 1807-~}$ 55092011000100002\&lng=pt\&tlng=pt. Acesso em: 23 maio2019.

SANCHO, Rosa et al. Indicadores bibliométricos utilizados en la evaluación de la ciencia y la tecnología. Revisión bibliográfica. Revista española de documentación científica, v. 13, n. 3-4, 1990. Disponível em: http://www.temarium.com/serlibre/recursos/ pdf/79059. Inteligencia\%20Competitiva.Lecturas. pdf\#page=77. Acesso em: 11 fev. 2019.

SILVA, Marcelo Moraes e et al. Pós-graduação em Educação Física: apontamentos sobre o livro "Dilemas e desafios da pós-graduação em Educação Física". Journal of Physical Education, v. 28, n. 1, p. 2840, 2017. Disponível em: http://www.periodicos. uem.br/ojs/index.php/RevEducFis/article/view/34228/19523. Acesso em: 13 fev. 2019.

SILVA, Junior Vagner Pereira da; GONÇALVES-SILVA, Luiza Lana; MOREIRA, Wagner Wey. Produtivismo na pós-graduação. Nada é tão ruim que não possa piorar. É chegada a vez dos orientandos! Movimento, v. 20, n. 4, p. 1423-1445, 2014. Disponível em: http://www.seer.ufrgs.br/Movimento/article/view/46187/0. Acesso em: 29 maio 2018.

SOUZA, Doralice Lange de; SILVA, Marcelo Moraes e; MOREIRA, Tatiana Sviesk. O perfil da produção científica online em Português relacionada às modalidades olímpicas e paralímpicas. Movimento, v. 22, n. 4, p. 1105-1120, 2016. Disponível em: http://www.seer.ufrgs.br/index.php/Movimento/article/view/64591. Acesso em: 29 mar. 2018.

STIGGER, Marco Paulo; SILVEIRA, Raquel da; MYSKIW, Mauro. O processo de avaliação da pós-graduação em educação física e ciências do esporte no Brasil e algumas de suas repercussões cotidianas. In: RECHIA, Simone et al. Dilemas e desafios da Pós-Graduação em educação física. ljuí: Ed. Unijuí, 2015. p. 15-56.

TAVARES, Otávio. Desafios e dilemas da pós-graduação em educação física: os estudos socioculturais e a Área 21. In: RECHIA, Simone et al. Dilemas e desafios da Pós-Graduação em educação física. ljuí: Ed. Unijuí, 2015. p. 219-234.

TULDER, Maurits Van et al. Updated method guidelines for systematic reviews in the cochrane collaboration back review group. Spine, v. 28, n. 12, p. 1290-1299, 2003.

VIVEIROS, Luís et al. Ciência do Esporte no Brasil: reflexões sobre o desenvolvimento das pesquisas, o cenário atual e as perspectivas futuras. Revista Brasileira de Educação Física e Esporte, v. 29, n. 1, p. 163-175, 2015. Disponível em: http://www. revistas.usp.br/rbefe/article/view/97352. Acesso em: 28 maio 2018.

WALLIN, Johan A. Bibliometric methods: pitfalls and possibilities. Basic \& clinical pharmacology \& toxicology, v. 97, n. 5, p. 261-275, 2005. Disponível em: https:// onlinelibrary.wiley.com/doi/full/10.1111/j.1742-7843.2005.pto 139.x. Acesso em: $21 \mathrm{fev}$. 2019. 


\section{Apoio:}

Ministério dos Esportes e Coordenação de Aperfeiçoamento de Pessoal de Nível Superior - Brasil (CAPES) - Código de Financiamento 001. This study was financed by the Brazilian Sport Ministry and by the Coordenação de Aperfeiçoamento de Pessoal de Nível Superior - Brasil (CAPES) - Finance Code 001 